\title{
Influence of Solute Molecular Diameter on Permeability-Selectivity Tradeoff of Thin-Film Composite Polyamide Membranes in Aqueous Separations
}

\author{
Xi Chen ${ }^{a}$, Chanhee Boo ${ }^{a}$, Ngai Yin Yip ${ }^{\text {a,b, }}$ \\ a Department of Earth and Environmental Engineering, Columbia University, New York, New York 10027-6623, United States \\ ${ }^{\mathrm{b}}$ Columbia Water Center, Columbia University, New York, New York 10027-6623, United States
}

\section{A R T I C L E I N F O}

\section{Keywords:}

solution-diffusion

membrane transport

thin-film composite polyamide

permeability-selectivity tradeoff

solute size

\begin{abstract}
A B S T R A C T
Fundamental understanding of the reverse osmosis (RO) transport phenomena is necessary for quantitative prediction of contaminant rejection and development of more selective membranes. The solution-diffusion (S-D) model predicts a tradeoff relationship between permeability and selectivity, and this tradeoff trend was recently reported for RO. But the first principles governing the relationship are not well understood for aqueous separation membranes. This study presents a framework to elucidate the underlying factors of the permeabilityselectivity tradeoff relationship in thin-film composite polyamide (TFC-PA) membranes. Water and solute permeabilities of membranes with a range of selectivities are examined using six nonelectrolyte solutes of various sizes and dimensions. The permeability-selectivity tradeoff trend, as defined by S-D, was observed for all six solutes. Crucially, the slopes of the tradeoff lines, $\lambda$, are found to be related to the solute and solvent (i.e., water) diameters, $d_{\mathrm{s}}$ and $d_{\mathrm{w}}$, respectively, by $\lambda=\left(d_{\mathrm{s}} / d_{\mathrm{w}}\right)^{2}-1$, consistent with the S-D framework established for gas separation membranes. Additionally, the intercepts of the tradeoff lines are shown to be also influenced by $d_{s}$. These results highlight that solute molecular diameter is a primary influence on the permeability-selectivity tradeoff for the permeants investigated in this study. Furthermore, a transport regime where solute permeation is only very weakly coupled to water transport, in addition to the conventional S-D, is identified for the first time. We demonstrate that the boundary delineating the two transport regimes can be determined by the solute diameter. The relationship between characteristic features of the "additional regime" and solute dimensions are analyzed. The study shows that the general principles of the S-D framework are applicable to TFC-PA membranes and the analysis quantified the principal role of solute size in governing RO transport. The experimental and analytical evidence suggest that nonelectrolyte solute transport can, in principle, be $a$ priori predicted using molecular diameter. Findings of this investigation provide new insights for understanding the transport mechanisms in osmotic membrane processes.
\end{abstract}

\section{Introduction}

Membrane technologies provide efficient aqueous separations and are widely used in water and environmental applications, including desalination, drinking water treatment, and wastewater reuse (Madaeni, 1999; Park et al., 2017; Peter-Varbanets et al., 2009; Radjenović et al., 2008; Werber et al., 2016b). Thin-film composite polyamide (TFC-PA) is widely considered to be the gold standard in productivity and selectivity performance for tight membranes capable of rejecting salts and low molecular weight solutes (Elimelech and Phillip, 2011; Greenlee et al., 2009; Werber et al., 2016b). The membrane comprises an aromatic polyamide selective layer on top of a highly porous polysulfone support with nonwoven polyester fibers embedded for mechanical robustness. At present, TFC-PA membranes are extensively used in reverse osmosis (RO) and nanofiltration (NF) applications, and are also investigated for emerging osmotic membrane technologies, such as forward osmosis, pressure retarded osmosis, and osmotically assisted/mediated reverse osmosis (Bartholomew et al., 2017; Chen et al., 2020; Petersen, 1993; Wang et al., 2020; Yip et al., 2010; Yip et al., 2011).

Fundamental understanding of the transport phenomena is crucial for accurate a priori modeling of solute passage (or rejection), to

\footnotetext{
* Corresponding author:

E-mail address: n.y.yip@columbia.edu (N.Y. Yip).
} 
quantitatively predict the fate of current and emerging micropollutants, and to guide the advancement of membrane-based technologies for more efficient and effective aqueous separations (Bolong et al., 2009; Kim et al., 2018; Koros and Zhang, 2017; Rodriguez-Narvaez et al., 2017; Werber et al., 2016b). In particular, the development of highly selective membranes has been highlighted as a key direction for improving RO and NF membranes (Park et al., 2017; Werber et al., 2016a). For examples, realizing RO membranes that can better reject boron will eliminate the requirement for a second-pass in seawater desalination and achieve substantial savings in energy and capital costs (Park et al., 2017); while the removal of trace contaminants and selective recovery of valuable constituents from water have been identified as critical separation challenges (Shannon et al., 2008; Sholl and Lively, 2016).

The solution-diffusion (S-D) model is currently the most widely accepted theoretical framework for polymeric salt-rejecting membranes, i.e., RO and tight NF (Baker, 2012; Geise et al., 2014; Wang et al., 2014a). In S-D, the membrane selective layer is considered to be nonporous. Permeants sorb (also termed partition or solubilize, hence solution) into the membrane, diffuse across the polymer film (hence diffusion), and desorb downstream (Paul, 2004; Wijmans and Baker, 1995). Importantly, the S-D model predicts a tradeoff between permeability and selectivity: increasing permeation rates is inevitably accompanied by a diminished ability of the membrane to differentiate between penetrants (Geise et al., 2014; Park et al., 2017). The permeability-selectivity tradeoff was first reported in gas separation membranes and is now a well-established concept in the membrane gas separation domain (Baker and Low, 2014; Freeman, 1999; Robeson et al., 2009). Recently, this tradeoff trend was also observed in TFC-PA RO and NF membranes for aqueous separations (Geise et al., 2011; Yang et al., 2019; Yip and Elimelech, 2011).

Although the observed tradeoff trend in aqueous separation membranes fits within the general construct of the S-D model, fundamental understanding of the first principles governing the permeability and selectivity relationship of TFC-PA membranes is still lacking. Past studies looked at the rejection of contaminants, such as, endocrine disrupting compounds and disinfection byproducts, and made significant contributions to the understanding of transport in RO and NF membranes (Breitner et al., 2019; Comerton et al., 2008; Doederer et al., 2014; Kibler et al., 2020; Kim et al., 2007; Kimura et al., 2003; Kimura et al., 2004; Kong et al., 2015; Miyashita et al., 2009; Radjenović et al., 2008; Steinle-Darling et al., 2007; Williams et al., 1999; Xie et al., 2012; 2014; Yangali-Quintanilla et al., 2010; Yangali-Quintanilla et al., 2009; Yoon et al., 2007; Zhang et al., 2020). However, there is still no cohesive theoretical framework relating the transport phenomena to permeant and polymer properties. In contrast, for gas separation membranes, the slope of the permeability-selectivity trend lines has been shown to be determined by intrinsic properties of the gas pair (ratio of kinetic diameters), whereas the intercept is related to polymer-specific parameters (Baker and Low, 2014; Freeman, 1999; Robeson et al., 2009).

In this study, we investigate the role of permeant physical properties in the permeability-selectivity tradeoff relationship in thin-film composite polyamide membranes. TFC-PA membranes are chemically modified to yield different selectivities and the water and solute permeabilities are evaluated using nonelectrolyte solutes with a range of molecular sizes. Transport characteristic elements are introduced to describe the principal features of different regimes of the permeabilityselectivity trend. The underlying factors governing transport are elucidated by relating the characteristic elements to solute size. Lastly, we reconcile the empirical evidence with theoretical principles to propose a fundamentals-based approach for describing solution-diffusion transport behavior in TFC-PA membranes, using intrinsic physical properties of the solute. This study provides insights for further understanding of the transport mechanisms in TFC-PA membranes.

\section{Solution-diffusion transport theory}

\subsection{Water and solute transport governing equations}

Water permeance coefficient, $A$, and solute permeance coefficient, $B$, Eqs. (1) and (2), respectively, are intrinsic transport properties of osmotic membranes (Baker, 2012).

$A=\frac{J_{\mathrm{w}}}{(\Delta P-\Delta \pi)}$

$B=\frac{J_{\mathrm{s}}}{\Delta c}$

Here, $J_{\mathrm{w}}$ and $J_{\mathrm{S}}$ are the water and solute fluxes, respectively, $\Delta P$ is the applied hydraulic pressure, and $\Delta \pi$ and $\Delta c$ are the transmembrane differences in osmotic pressure and concentration, respectively. Note that $A$ and $B$ are proportionality coefficients that relate driving forces (i.e., $\Delta P-\Delta \pi$ and $\Delta c$, respectively) to fluxes and can be empirically determined in filtration experiments. As explication of the underlying transport mechanism is not necessary to characterize $A$ and $B$, the permeance coefficients are, thus, phenomenological descriptors of the membrane process.

In the classical solution-diffusion transport mechanism, the permeants (water or solute) partition into the nonporous membrane matrix, diffuse through the polymeric network, and desorb downstream (Baker, 2012; Wijmans and Baker, 1995). Permeability of the membrane to penetrant component $i$ (water or solute), $P_{i}$, thus can be expressed as the product of the sorption (also termed partition and solubility) coefficient, $K_{i}$, and the diffusivity, $D_{i}$, in the membrane phase, i.e., $P_{i}=K_{i} D_{i}$. Through the S-D transport framework, permeance coefficients, $A$ and $B$, can be related to effective membrane permeabilities for water $\left(P_{\mathrm{w}}\right)$ and solute $\left(P_{\text {s }}\right)$, respectively (Geise et al., 2011):

$A=\frac{P_{\mathrm{w}}}{L} \frac{v_{\mathrm{w}}}{R T}$

$B=\frac{P_{\mathrm{s}}}{L}$

where $L$ is the thickness of the membrane selective layer, $v_{\mathrm{w}}$ is the molar volume of water, $R$ is the gas constant, and $T$ is the absolute temperature. Detailed derivations can be found in a previous study (Geise et al., 2011) and are also presented in Appendix A. The solution-diffusion mechanism provides the theoretical underpinnings for the water and solute transport phenomena through Eqs. (3) and ((4). This classical framework of S-D transport theory had been further modified to yield variant models, including solution-diffusion imperfection (Sherwood et al., 1967; Yaroshchuk, 1995), extended solution-diffusion (Wang et al., 2014b), and solution-diffusion-convection (Verliefde et al., 2009a). However, these alternative versions are not employed in this study as the conventional S-D theory is found to be adequate in explaining the experimental findings.

\subsection{Tradeoff between water permeability and solute selectivity}

Permeability-selectivity tradeoff has been empirically demonstrated for thin-film composite polyamide membranes (Geise et al., 2011; Werber et al., 2016b; Yang et al., 2019; Yip and Elimelech, 2011). Accordingly, an empirical relationship was proposed to relate the effective water permeability, $P_{\mathrm{w}}$, and the water/solute selectivity, $P_{\mathrm{w}} / P_{\mathrm{s}}$, of the tradeoff (Geise et al., 2011):

$$
\frac{P_{\mathrm{w}}}{P_{\mathrm{s}}}=\frac{\beta}{P_{\mathrm{w}}{ }^{\lambda}}
$$

where $\beta$ and $\lambda$ are empirical fitting parameters. Substituting Eqs. (3) and (4) into Eq. (5) yields (Yip and Elimelech, 2011): 
Table 1

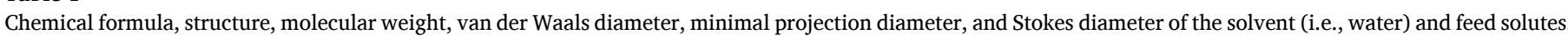

\begin{tabular}{|c|c|c|c|c|c|c|c|}
\hline Solute & Abbreviation & $\begin{array}{l}\text { Chemical } \\
\text { Formula }\end{array}$ & Chemical Structure & $\begin{array}{l}\text { Molecular } \\
\text { Weight }(\mathrm{g} / \mathrm{mol})\end{array}$ & $\begin{array}{l}\text { van der Waals } \\
\text { diameter, } d^{v}(\AA)\end{array}$ & $\begin{array}{l}\text { Minimal projection } \\
\text { diameter, } d^{\mathbf{p}}(\AA)\end{array}$ & $\begin{array}{l}\text { Stokes } \\
\text { diameter, } d^{S}(\AA)\end{array}$ \\
\hline Water & N/A & $\mathrm{H}_{2} \mathrm{O}$ & $\mathrm{H} 、$ & 18 & 3.34 & 3.50 & 2.76 \\
\hline $\begin{array}{c}\text { Ethylene } \\
\text { glycol }\end{array}$ & $\mathrm{Eg}$ & $\mathrm{C}_{2} \mathrm{H}_{6} \mathrm{O}_{2}$ & $\mathrm{HC}$ & 62 & 4.92 & 5.12 & 3.60 \\
\hline Trioxane & $\operatorname{Tr}$ & $\mathrm{C}_{3} \mathrm{H}_{6} \mathrm{O}_{3}$ & & 90 & 5.31 & 6.44 & 3.82 \\
\hline Erythritol & $\mathrm{Er}$ & $\mathrm{C}_{4} \mathrm{H}_{10} \mathrm{O}_{4}$ & & 122 & 6.01 & 6.72 & 5.26 \\
\hline Xylose & $\mathrm{Xy}$ & $\mathrm{C}_{5} \mathrm{H}_{10} \mathrm{O}_{5}$ & & 150 & 6.26 & 7.30 & 5.80 \\
\hline Glucose & $\mathrm{Gl}$ & $\mathrm{C}_{6} \mathrm{H}_{12} \mathrm{O}_{6}$ & $\mathrm{H}$ & 180 & 6.66 & 8.02 & 6.14 \\
\hline Lactose & $\mathrm{La}$ & $\mathrm{C}_{12} \mathrm{H}_{22} \mathrm{O}_{11}$ & & 342 & 8.20 & 10.02 & 9.05 \\
\hline
\end{tabular}

$B=\left(\frac{360 L^{\lambda}}{\beta}\right)\left(\frac{R T}{v_{\mathrm{w}}}\right)^{\lambda+1} A^{\lambda+1}$

Here, the units of $A$ and $B$ are $\mathrm{L} \mathrm{m}^{-2} \mathrm{~h}^{-1}$ bar $^{-1}$ and $\mathrm{L} \mathrm{m}^{-2} \mathrm{~h}^{-1}$, respectively, which are the most widely used in aqueous separations, while the factor of 360 accounts for the units conversion between permeabilities, $P_{\mathrm{w}}$ and $P_{\mathrm{S}}\left(\mathrm{cm}^{2} / \mathrm{s}\right)$, and water and solute permeance coefficients. Eq. (6) indicates that, under the S-D transport framework, the permeance coefficients are intrinsically linked, specifically, $B \propto A^{\lambda+1}$. Conversely, empirical observation of a linear relationship between $B$ and $A^{\lambda+1}$ would reciprocally support solution-diffusion as the principal transport mechanism. Indeed, a previous study reported good agreement of experimental data of water and solute ( $\mathrm{NaCl}$ salt) permeance coefficients for TFC-PA membranes with Eq. (6) (Yip and Elimelech, 2011), thus providing initial evidence that transport is governed by the solution-diffusion mechanism.

\section{Materials and methods}

\subsection{Materials and chemicals}

Flat-sheet seawater reverse osmosis (RO) desalination membranes from DOW Filmtec (SW30-HR, Midland, MI) were used for all experiments. The thin-film composite (TFC) RO membrane comprises a polyamide selective layer supported by a highly porous polysulfone layer with non-woven polyester fabric embedded for mechanical integrity. To remove possible coatings applied by the manufacturer for surface protection and preservation, the membrane was soaked in $25 \mathrm{v} / \mathrm{v} \%$ isopropanol, followed by thorough rinsing with deionized (DI) water. The cleaned membrane coupons were stored in DI water at $4{ }^{\circ} \mathrm{C}$ before chemical modification of the polyamide layer to alter permeability and selectivity. The oxidizing reagent for membrane modification was prepared by diluting $5.0 \mathrm{w} / \mathrm{w} \%(0.67 \mathrm{M})$ aqueous sodium hypochlorite solution (Fisher Scientific, PA) in DI water. Six nonelectrolyte solutes, ethylene glycol (Eg), 1,3,5-trioxane (Tr), erythritol (Er), D-xylose (Xy), $\alpha$-glucose (Gl), and $\alpha$-lactose (La), used for characterization of membrane solute permeability were obtained from FisherScientific (Hanover
Park, IL) and are of ACS analytical grade. Pertinent properties of the solutes and solvent (i.e., water) are listed in Table 1. All other chemicals used in this study are of ACS analytical grade.

\subsection{Polyamide layer modification}

Water and solute permeabilities of the polyamide membrane layer can be thoughtfully altered using a chlorine-alkaline chemical modification technique by careful control of the reaction conditions, specifically the chlorine concentration and reactant exposure time (Gu et al., 2012; Jons et al.; Yip and Elimelech, 2011). In general, higher chlorine concentrations or longer treatment durations yield greater elevations in $A$ and $B$, i.e., larger increase in permeability but also more pronounced reduction in selectivity. The alcohol-washed membranes were immersed in aqueous $\mathrm{NaOCl}$ solution with concentrations of 100-10,000 ppm for 1-2 h. $\mathrm{pH}$ of the hypochlorite solution was adjusted to 7.0 by dosing with $6 \mathrm{M} \mathrm{HCl}$. The chlorine-treated membranes were washed twice with DI water and then stored in $0.1 \mathrm{M} \mathrm{NaOH}$ for $16 \mathrm{~h}$. Membranes were then rinsed with DI water three times to remove residual $\mathrm{NaOH}$ and stored in DI water at $4{ }^{\circ} \mathrm{C}$ before test. Reaction conditions of the modification treatment are summarized in Table D1 in the Appendix D.

\subsection{Characterization of membrane water and solute permeances}

Membrane transport properties were characterized using a custombuilt crossflow RO setup with effective membrane area of $19.5 \mathrm{~cm}^{2}$. Water permeance coefficient, $A$, was determined using DI water as the feed stream, i.e., no solutes. Steady-state pure water flux, $J_{\mathrm{w}}^{\mathrm{DI}}$, under hydraulic pressure, $\Delta P$, of $27.6 \mathrm{bar}$ ( $400 \mathrm{psi}$ ) was obtained by measuring the rate of change in the permeate weight and water permeance coefficient is calculated using $A=J_{\mathrm{w}}^{\mathrm{DI}} / \Delta P$ (i.e., Eq. (1) with $\Delta \pi=0$ ). Permeate fluxes were monitored using a FlowCal 5000 digital flowmeter (TovaTech, $\mathrm{NJ}$ ) with detection limit of $0.001 \mathrm{~mL} / \mathrm{min}$ (equivalent to $J_{\mathrm{w}}$ of $0.03 \mathrm{~L} \mathrm{~m}^{-2} \mathrm{~h}^{-1}$ ). During steady state, the permeate was collected and weighed using a precision microbalance to determine $J_{\mathrm{w}}$ (resolution of $0.0001 \mathrm{~L} \mathrm{~m}^{-2} \mathrm{~h}^{-1}$ ).

Solute permeances of the different nonelectrolyte solutes were 


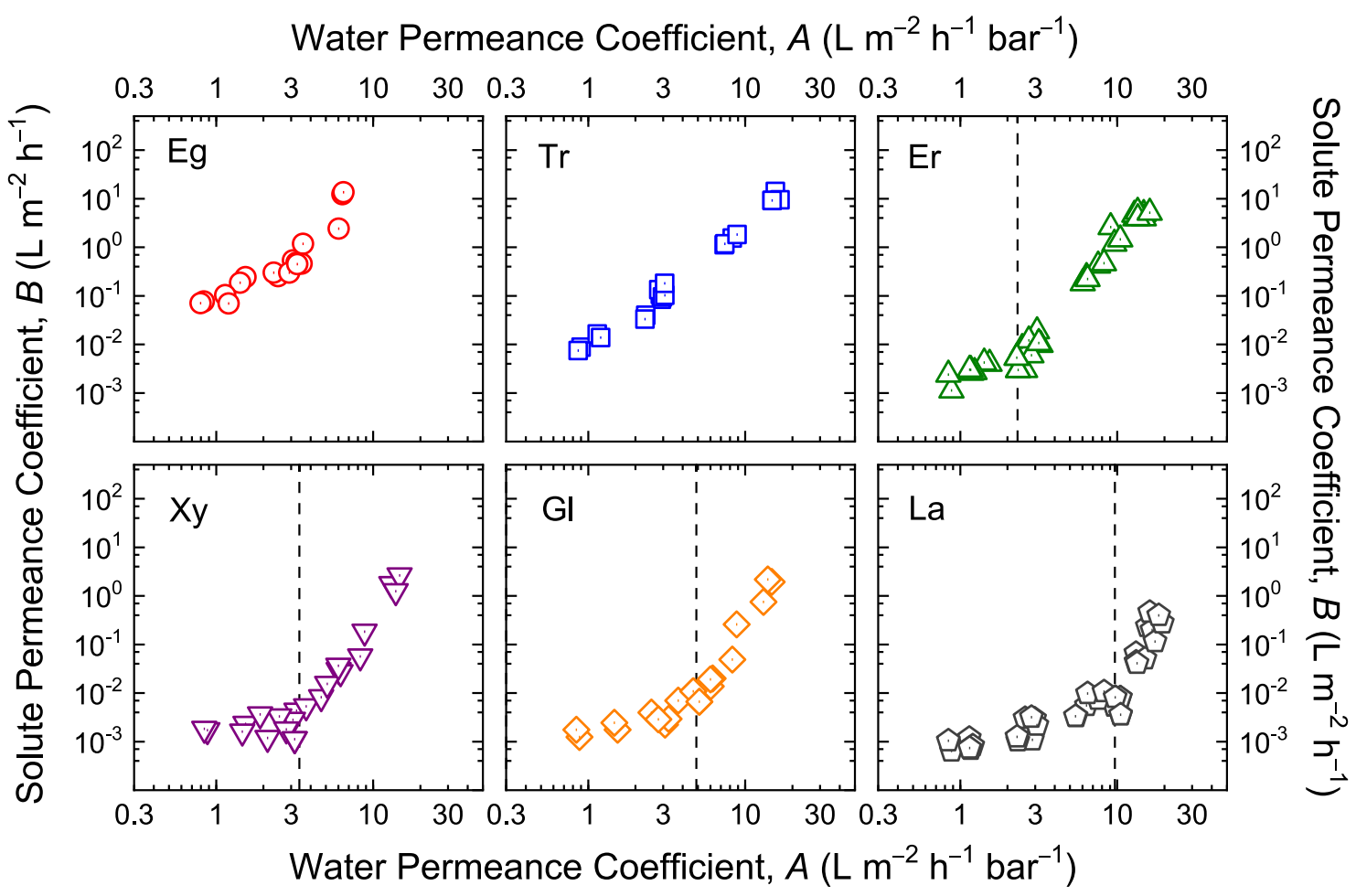

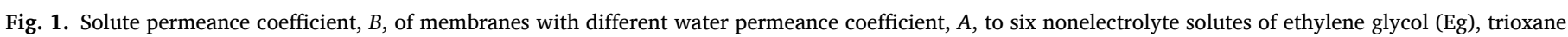

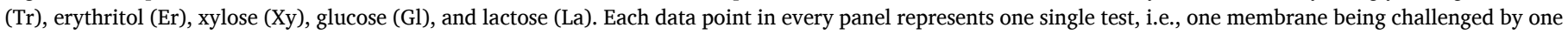
solute. Both horizontal and vertical axes are on logarithmic scale. Vertical dashed lines approximately demarcate the different transport regimes.

characterized by recording permeate water flux, $J_{\mathrm{w}}$, and solute concentration, $c_{\mathrm{p}}$, of RO tests at steady state. Both the concentrate and permeate streams were recirculated back to the feed tank during equilibration. Only during data collection was the permeate stream not cycled backed to the feed reservoir. Feed solutions were prepared by dissolving each solute in DI water to yield total organic carbon (TOC) concentration of $40 \mathrm{mg}-\mathrm{C} / \mathrm{L}$. Hydraulic pressure, $\Delta P$, of 27.6 bar $(400$ psi) and crossflow velocity of $25.4 \mathrm{~cm} / \mathrm{s}$ were applied to all tests, and were monitored by an in-line pressure gauge and a volumetric flowmeter, respectively. For each test, $J_{\mathrm{w}}$ and $c_{\mathrm{p}}$ are the mean of the sample collected over 15-30 min. The entire RO system, including the membrane and permeate tubings, was flushed, once-through, with DI water under $\Delta P=27.6$ bar for at least $15 \mathrm{~min}$ to purge any residual solutes from the system and bring the TOC reading back to background levels. Solute permeance coefficient, $B$, is determined using Eqs. (1) and (2), and the modified van't Hoff relation (Baker, 2012), incorporating the effects of concentration polarization:

$B=\frac{c_{\mathrm{p}} J_{\mathrm{w}}}{c_{\mathrm{f}, \mathrm{m}}-c_{\mathrm{p}}}=\frac{c_{\mathrm{p}} J_{\mathrm{w}}(\phi \nu R T)}{\Delta P-\left(J_{\mathrm{w}} / A\right)}$

where $c_{\mathrm{f}, \mathrm{m}}$ is solute concentration at the solution-membrane interface, $\phi$ is the solute osmotic coefficient, and $\nu$ is the number of species each solute molecule dissociates into (Robinson and Stokes, 2002). For the relatively low concentration of all the nonelectrolyte (i.e., neutral) solutes investigated in this study, both $\phi$ and $\nu$ are taken to be unity (Bonner and Breazeale, 1965; Robinson and Stokes, 2002; Rudan-Tasic and Klofutar, 2003; Stokes and Robinson, 1966; Uedaira and Uedaira, 1969). Permeate concentration, $c_{\mathrm{p}}$, is determined by evaluating the TOC concentration using a Hach QbD1200 TOC analyzer (Loveland, CO), with detection range of $0.4 \mathrm{ppb}$ to $100 \mathrm{ppm}$, with subtraction of the background TOC concentration of the solvent, i.e., DI water. Additionally, background concentration attributed to the RO system is characterized by measuring the TOC of permeates from membranes with different permeabilities using DI water as the feed under 27.6 bar. All the RO experiments were carried out at $25^{\circ} \mathrm{C}$ and $\mathrm{pH}$ of the feed solution at the end of the experimental run was recorded to assess for possible solute protonation or deprotonation.

\subsection{Determination of solute molecular diameters}

Van der Waals diameters $\left(d^{\mathrm{V}}\right)$ and minimal projection diameters $\left(d^{\mathrm{P}}\right)$ of the six nonelectrolyte solutes are obtained from MarvinSketch software (MarvinSketch). The Stokes diameter $\left(d^{S}\right)$ is calculated using Eq. (8), where $k$ is the Boltzmann constant, $T$ is absolute temperature, $\mu_{\mathrm{w}}$ is viscosity of the solvent, and $D$ is the diffusion coefficient of the solute in the bulk solution (Robinson and Stokes, 2002). Diffusivity can be determined using the Wilke-Chang equation, Eq. (9), where $\varphi$ is the association parameter ( 2.6 for water), $M_{\mathrm{W}}$ is the molar weight of water, and $V_{s}$ is molar volume of the solute (Bird et al., 2007; Geankopolis, 1993). Molecular diameters of the six solutes and water (solvent) are listed in Table 1.

$d^{\mathrm{S}}=2 \times \frac{k T}{6 \pi \mu_{\mathrm{w}} D}$

$D=1.173 \times 10^{-16} \frac{T \sqrt{\varphi M_{\mathrm{w}}}}{\mu_{\mathrm{w}} V_{\mathrm{s}}^{0.6}}$

\section{Results and discussion}

\subsection{Identification of solution-diffusion transport and a second regime}

Commercial RO membranes were chemically modified to yield a range of different permeabilities and selectivities, and the water and solute permeance for six different nonelectrolyte solutes were carefully characterized. Feed solution pHs at the end of the experiments $(\approx 5.76$ 6.23) are considerably lower than the $\mathrm{p} K_{\mathrm{a}}$ values (11.25-14.83, Table D2 in the Appendix D) and, thus, all solutes remain as neutral species (i.e., not deprotonated) throughout the experiment. Using DI water as the 


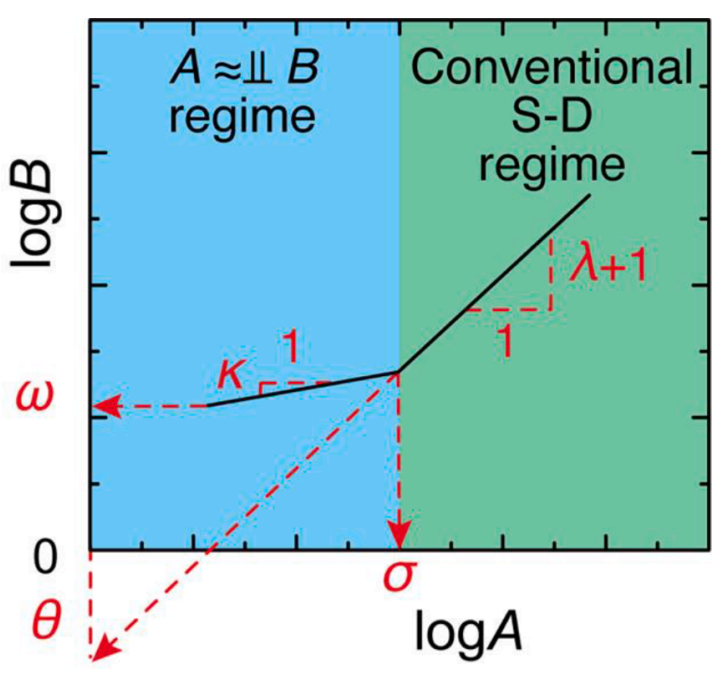

Fig. 2. Schematic depicting the generalized relationship between $\log B$ and $\log$ $A$ under different transport regimes of the thin-film composite polyamide membranes. Transport is delimited into the putative solution-diffusion mechanism (right green shaded area) and a previously unreported regime where $B$ is only very weakly dependent on $A$ (left blue shaded area). Transport characteristic elements (indicated by red font labels) of slope $(\lambda+1)$ and intercept $\theta$ are assigned to the S-D regime, whereas $\omega$ and $\kappa$ describe the trend-line of the $A \approx \Perp$ $B$ transport regime. Element $\sigma$ denotes the $\log A$ threshold demarcating the two regimes.

feed, background TOC concentrations from the RO system are effectively equal to the TOC content of the feed tank, and have practically no variation between membranes with different permeabilities, indicating that potential TOC contribution from the system is relatively insignificant relative to the permeate. Solute permeance coefficient, $B$, as a function of water permeance coefficient, $A$, on $\log$-log scales are shown in Fig. 1 for the six solutes. The $A$ and $B$ obtained correspond to permeabilities/selectivities of membranes from seawater reverse osmosis to tight nanofiltration (Baker, 2012; Mulder, 2012). The potential impacts of convective transport are examined in Appendix B and are shown to be marginal (Fig. B1), as expected for TFC-PA membranes with low water swelling (Geise et al., 2010; Geise et al., 2011; Geise et al., 2014).

Fig. 1 shows the two smallest solutes of ethylene glycol, Eg, and trioxane, Tr, (molecular weight of 62 and $90 \mathrm{~g} / \mathrm{mol}$, respectively, Table 1), exhibiting linear relationships over the entire $A-B$ range investigated. As discussed earlier, solution-diffusion transport predicts that $\log B$ is directly proportional to $\log A$ (Eq. (6)), with $\lambda+1$ being the proportionality factor, i.e., slope of line. The experimental data is, thus, consistent with the solution-diffusion mechanism. For the relatively larger solutes of erythritol (Er), xylose (Xy), glucose (Gl), and lactose (La) with molecule weights of 122-342 $\mathrm{g} / \mathrm{mol}$, the same linear trends are also clearly observed above a certain $A$ (right side of vertical dashed lines in Fig. 1). This result indicates that the governing transport mechanism for sufficiently permeable membranes is in agreement with S-D.
However, for Er, Xy, Gl, and La transport below the threshold $A$ (left of the vertical dashed lines), the relationship between $B$ and $A$ appears to the fundamentally different as inclusion of these points in the data set yielded significantly poorer linear regression fittings. This implies that the underlying transport in this regime is a deviation, or possibly even departure, from the current understanding of solution-diffusion mechanism governing the membrane at higher permeabilities. A similar phenomenon was also empirically observed in a collated dataset for electrolyte solute $(\mathrm{NaCl})$ transport across TFC-PA membranes (Yang et al., 2019). We term this second transport the " $A \approx \Perp B$ " regime, i.e., $A$ is approximately independent of $B$. In the following subsections, discussion is focused on solution-diffusion, the main governing transport mechanism for the nonelectrolyte solutes investigated (when $A$ is adequately high); and then analysis of the $A \approx \Perp B$ transport regime, which emerges to be the primary phenomenon for solutes with higher molecular weights at relatively low membrane permeabilities, is presented.

\subsection{Transport characteristic elements of the regimes}

Relationship between solute and water transport presented in Fig. 1 can be generalized by Fig. 2. We propose that transport is divided into two regimes (left and right panels of Fig. 2), delineated by a threshold water permeability (boundary separating the two panels). Above the threshold permeability, in the high- $A$ regime, the $\log B-\log A$ relationship is linear, as clearly seen for all six solutes investigated. We posit that classical solution-diffusion is the dominant transport mechanism in this regime. Whereas below the threshold, $B$ is only very weakly influenced by $A$, as denoted by the almost flat line of the left panel. We postulate that transport in this regime is significantly different from solutiondiffusion of the right panel, and identify this as the " $A \approx \Perp B$ " regime. For the TFC-PA membranes used in this study, this second transport mechanism was only observed for the four larger solutes.

Features of the transport regimes can be described by graphical elements of the $\log A-\log B$ lines, which we term "transport characteristic elements" (indicated as red font labels in Fig. 2). Based on the solutiondiffusion framework of Eq. (6), the slope and intercept of the $\log A-\log B$ line for the conventional S-D regime are $\lambda+1$ and $\theta=(\lambda+$ 1) $\log \left(R T / v_{\mathrm{w}}\right)+\lambda \log (360 L)-\log \beta$, respectively. The $\log A$ threshold delineating the two transports mechanisms is represented by $\sigma$. The exact trend between $\log B$ and $\log A$ in the $A \approx \Perp B$ regime, however, is more difficult to conclusively identify due to limited experimental data points (only four of the six solutes investigated displayed the $A \approx \Perp B$ transport regime, and the smaller solutes of $\mathrm{Er}$ and Xy exhibited the behavior in relatively narrow $\log A$ ranges). As such, we postulate that either $\log A-\log B$ is governed by a linear relation, albeit possessing a smaller slope, $\kappa$, relative to $S$-D regime, or $\log B$ is constant at $\omega$ as $\log A$ varies (i.e., horizontal line indicating water permeability increases without solute permeability rising).

Values of the transport characteristic elements are obtained from linear regressions of the data presented in Fig. 1 and are summarized in Table 2. Very good fits were obtained for the solution-diffusion regime, as indicated by the high coefficients of determination, $R^{2}$, of at least

Table 2

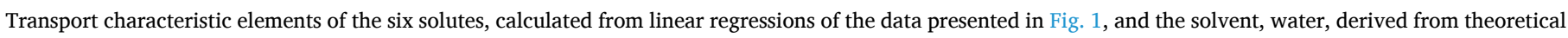
transport equations (detailed in Appendix C).

\begin{tabular}{|c|c|c|c|c|c|c|c|}
\hline \multirow[t]{2}{*}{ Solute } & \multicolumn{3}{|c|}{ Conventional S-D Regim> } & \multicolumn{4}{|c|}{$A \approx \Perp B$ Regime } \\
\hline & $\lambda+1$ & $\theta$ & $R^{2}$ & $\sigma$ & $\omega$ & $\kappa$ & $R^{2}$ \\
\hline Water & 1.00 & 3.14 & & \multicolumn{4}{|c|}{ Not applicable } \\
\hline Ethylene glycol (Eg) & 2.22 & -1.04 & 0.824 & \multicolumn{4}{|c|}{ Not observed } \\
\hline Trioxane (Tr) & 2.54 & -2.11 & 0.984 & \multicolumn{4}{|c|}{ Not observed } \\
\hline Erythritol (Er) & 3.95 & -3.84 & 0.980 & $0.365 \pm 0.006$ & $-2.55 \pm 0.03$ & 0.836 & 0.418 \\
\hline Xylose (Xy) & 4.52 & -5.01 & 0.969 & $0.529 \pm 0.039$ & $-2.75 \pm 0.02$ & 0.396 & 0.069 \\
\hline Glucose (Gl) & 5.10 & -5.68 & 0.958 & $0.688 \pm 0.027$ & $-2.83 \pm 0.11$ & 0.704 & 0.566 \\
\hline Lactose (La) & 6.34 & -8.52 & 0.862 & $0.985 \pm 0.003$ & $-3.14 \pm 0.04$ & 0.997 & 0.828 \\
\hline
\end{tabular}



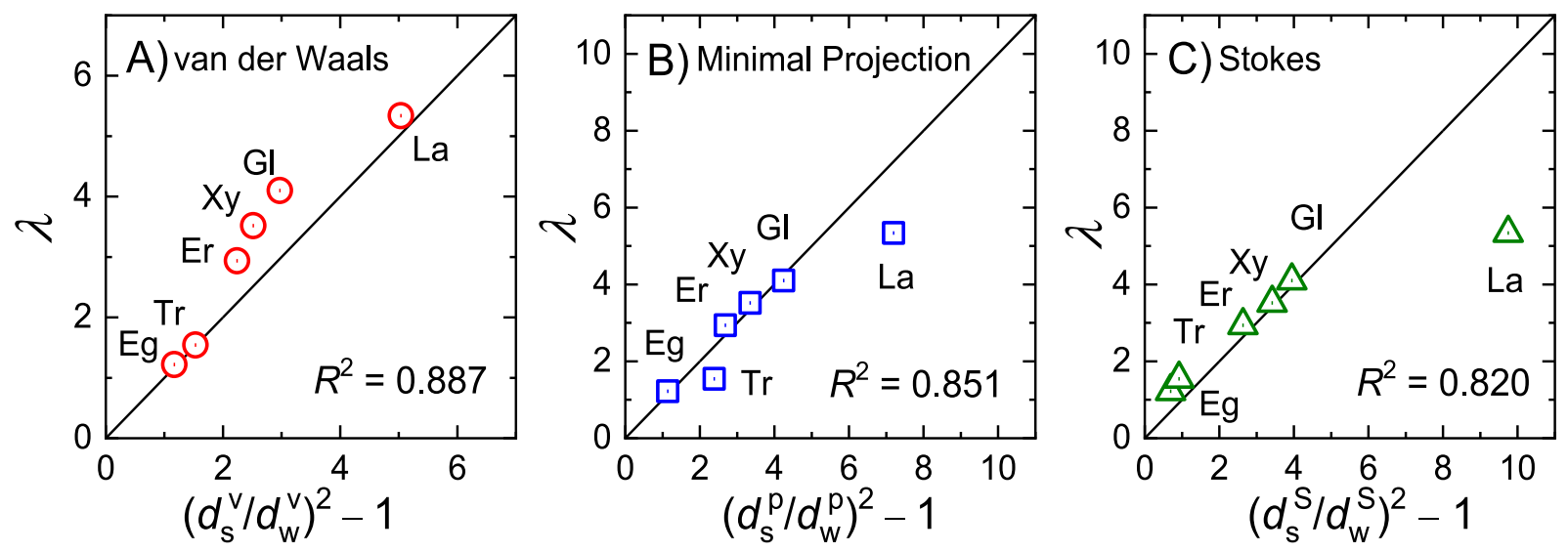

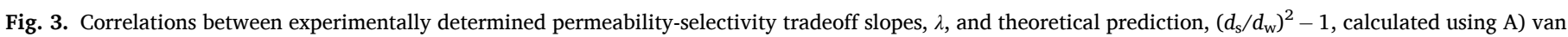

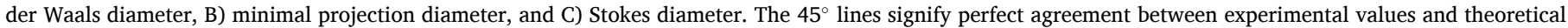

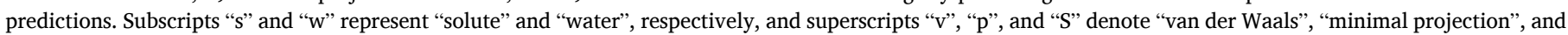

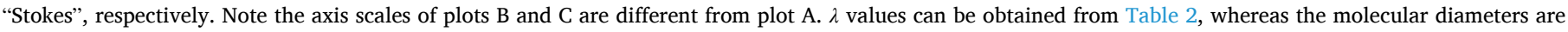
summarized in Table 1.

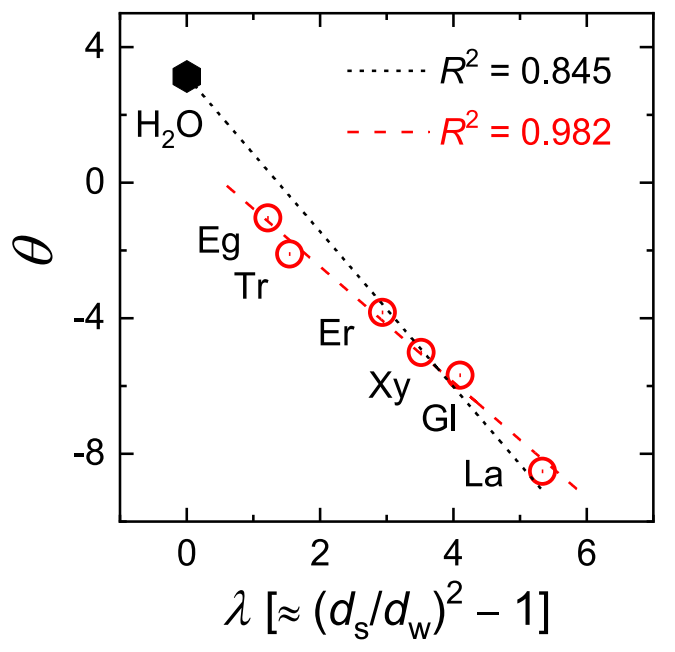

Fig. 4. Correlation between S-D transport characteristic elements, $\theta$ and $\lambda$. Red dashed and black dotted lines denote fitting results from linear regressions, without fixed intercept and with fixed intercept of $\log \left(R T / \nu_{\mathrm{w}}\right)$, respectively.

0.824 (above 0.95 for four of the six solutes). On the other hand, $R^{2}$ values for the linear regressions of the $A \approx \Perp B$ regime are comparatively lower ( $<0.60$ for three of the four solutes). However, the coefficients of variation (ratio of standard deviation to mean) are relatively small (7.1$18.1 \%$ ), thus, lending support to the conjecture that water permeability is practically independent of solute permeability in the $A \approx \Perp B$ regime. For analysis, elements of the S-D regime, $\lambda+1$ and $\theta$, for the solvent, i.e., water, are also included (derivations detailed in Appendix C). The $\lambda$ of 0 and $\beta$ of 1 (equivalently, $\theta=\log R T / v_{\mathrm{w}}$ ) reflect that the membranes do not exhibit selectivity when the feed is pure water. Next, the relationship of the transport characteristic elements to intrinsic solute properties are analyzed and discussed.

\subsection{Solute size is a principal factor governing transport in the solution- diffusion regime}

For polymeric membranes separating a binary mixture of gas $A$ and $B$, the solution-diffusion model establishes that the permeabilityselectivity tradeoff slope, $\lambda_{\mathrm{A} / \mathrm{B}}$, is related to the gas molecule kinetic diameters, $d$, by $\lambda_{\mathrm{A} / \mathrm{B}}=\left(d_{\mathrm{B}} / d_{\mathrm{A}}\right)^{2}-1$ (Freeman, 1999; Robeson, 2008; Sanders et al., 2013). Underlying basis of the relationship is detailed in literature (Freeman, 1999; Teplyakov and Meares, 1990), and the main derivation steps and equations are summarized in Appendix A. We extend this principle to aqueous separation membranes for the tradeoff slope between solvent (water) and solute: $\lambda=\left(d_{\mathrm{s}} / d_{\mathrm{w}}\right)^{2}-1$, where $d_{\mathrm{s}}$ and $d_{\mathrm{w}}$ are diameters of the solute and water molecules, respectively. Relationships between $\lambda$ and $\left(d_{s} / d_{\mathrm{w}}\right)^{2}-1$ for the six solutes are shown in Fig. 3. Three different molecular diameters are evaluated, namely, van der Waals diameter $\left(d^{\mathrm{v}}\right)$, minimal projection diameter $\left(d^{\mathrm{P}}\right)$, and Stokes diameter $\left(d^{S}\right)$. The van der Waals diameter represents the equivalent spherical diameter of the unbonded bare molecule (Batsanov, 2001), the minimal projection diameter is derived from the projected area of the structural conformation (unbounded bare molecule) (MarvinSketch), and the Stokes diameter characterizes the hydrodynamic size of the solute in bulk-phase solution (Baker, 2012; Marcus, 2015; Robinson and Stokes, 2002). The diameters are summarized in Table 1 and the three different molecular $d$ differ by $22.2-68.5 \%$. The $45^{\circ}$ lines in Fig. 3 denote perfect fits whereas the coefficients of determination, $R^{2}$, are representative of the accuracy of using molecular diameters to predict permeability-selectivity tradeoff slopes.

Overall, experimental $\lambda$ exhibits very good agreement with $\left(d_{\mathrm{S}}\right)$ $\left.d_{\mathrm{w}}\right)^{2}-1$ for the three molecular diameters examined, with strong linear correlations: $R^{2}$ of $0.887,0.851$, and 0.820 for van der Waals diameter, minimal projection diameter, and Stokes diameter, respectively. The excellent predictions of the permeability-selectivity tradeoff slopes with molecular diameters strongly indicate that solute size is the principal factor governing S-D transport of the nonelectrolyte solutes investigated here. This finding is supported by a recent study that reported molecular size as being more suitable for evaluating rejection of small uncharged compounds in RO than molecular weight (Fujioka et al., 2019), which has conventionally been utilized as the primary characteristic to relate transport of organic molecules across membranes (Bellona et al., 2004). Specifically, the study observed that RO rejection of uncharged solutes is highly correlated with minimal projection area of the molecule, which is linearly proportional to the term $\left(d_{\mathrm{s}} / d_{\mathrm{w}}\right)^{2}-1$ (Fujioka et al., 2019), thus corroborating our finding.

Fig. 3 shows that the permeability-selectivity tradeoff slope, $\lambda$, or, equivalently, the power law factor relating water and solute permeances, $\lambda+1$, can be directly derived from the intrinsic molecular diameters. Because $\lambda$ increases with the square of solute diameter, the permeability of a larger molecule rises more substantially (i.e., greater deterioration in selectivity) with higher water permeability of the TFCPA membrane compared to smaller solutes. $\lambda$ for the largest solute of $\mathrm{La}$ appears to be less accurately predicted using minimal projection and Stokes diameters. Lactose is a disaccharide and intramolecular hydrogen bonding can change the molecular conformation (Carçabal et al., 2005). 


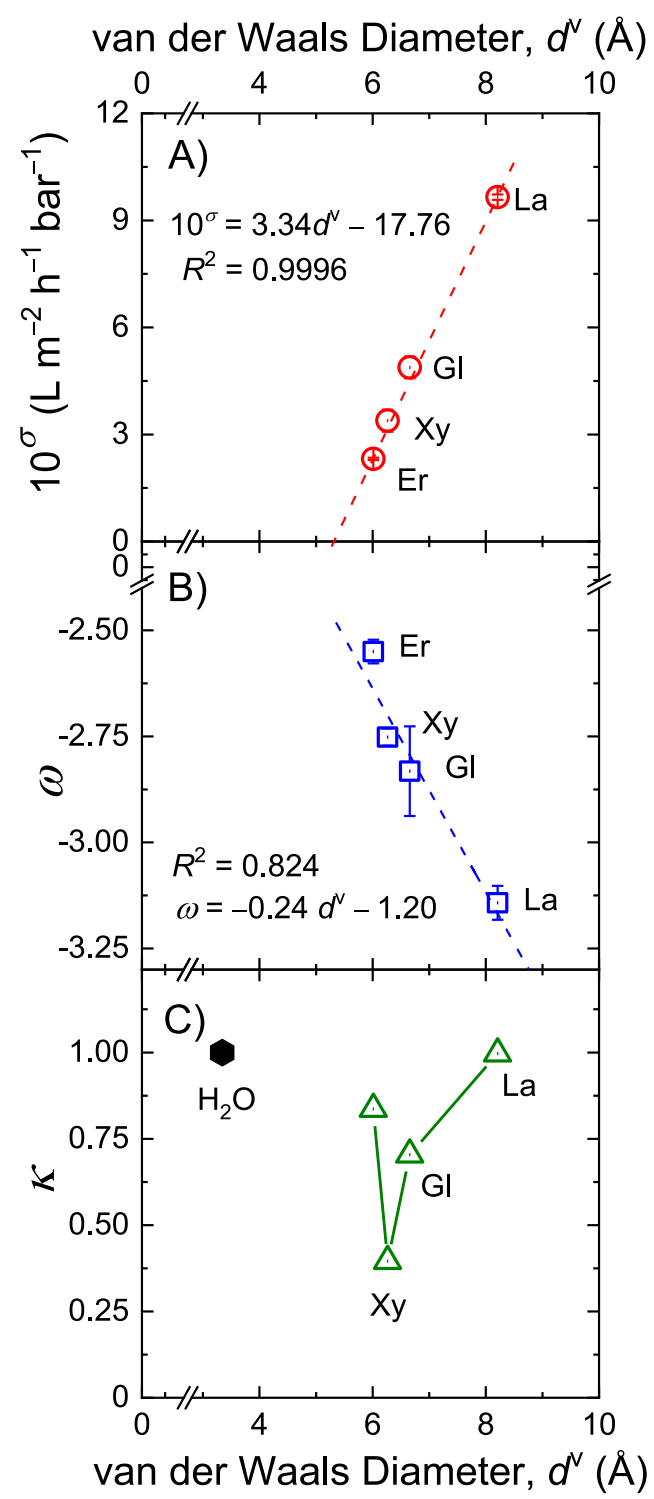

Fig. 5. Transport characteristic elements A) $\sigma$, presented as $10^{\sigma}$, B) $\omega$, and C) $\kappa$ of the transition and $A \approx \Perp B$ transport regime as a function of the van der Waals diameter, $d^{v}$, for the four larger solutes of erythritol (Er), D-xylose (Xy), $\alpha$-glucose (Gl), and $\alpha$-lactose (La).

Additionally, compared with the other five solutes, La possesses more oxygen atoms that can form $\mathrm{H}$-bonds with the polyamide selective layer (detailed in later discussions), likely leading to impeded transport. The overprediction of $\lambda$ using $d^{\mathrm{p}}$ and $d^{\mathrm{S}}$ is possibly attributed to these effects. Lastly, we note that while van der Waals diameter yielded the best fit, it would be premature to conclude that $d^{\mathrm{v}}$ is the elementary dimension governing S-D transport as the sample size is relatively small (six) and more rigorous investigations are needed.

Membrane transport of neutral organic solutes (i.e., nonelectrolytes) is influenced by physicochemical properties of the solute and membrane, and solute-membrane interactions (Dražević et al., 2017; Kim et al., 2007; Verliefde et al., 2009b; Zhang et al., 2020). Under the neutral condition $(\mathrm{pH}=7)$ of the chlorine-alkaline treatment employed in this investigation, chlorine incorporation ( $N$ - and ring-chlorination) followed by polyamide degradation and chlorination-promoted hydrolysis are expected to be significant (Verbeke 2017). The reactions elevate the polyamide selective layer permittivity (Stolov and Freger, 2019; Verbeke et al., 2017), reducing solvation energy barrier of the solutes according to the Born model, thus facilitate solute sorption into the membrane from the bulk aqueous phase (Anslyn and Dougherty, 2006; Bowen and Welfoot, 2002; Zhang and Geise, 2016). The increase in polyamide hydrophilicity due to chlorination-promoted hydrolysis (Stolov and Freger, 2019; Verbeke et al., 2017) would result in greater solute-membrane affinity of the six solutes as the octanol-water partition coefficients are all well below unity. Further, the six solute molecules in this study possess multiple oxygen atoms (Table 1), which can behave as hydrogen bond donors (hydroxyl groups in Eg, Er, Xy, Gl, and La) or acceptors (in Tr), and form H-bonds with the PA matrix. Both the increases in hydrophilicity and hydrogen bonding also favor the partitioning of solutes into the membrane matrix (Epsztein et al., 2020; Hannesschlaeger et al., 2019). However, these interactions are relatively weak (Anslyn and Dougherty, 2006) and cannot completely explain the 2-3 orders of magnitude enhancement in solute permeance $B$ as membrane water permeance increases (i.e., the tradeoff trends observed in the conventional S-D regime of Fig. 1). However, we note that these solute-membrane interactions may account for the deviations between the predictive term, $\left(d_{\mathrm{s}} / d_{\mathrm{w}}\right)^{2}-1$, and the experimental $\lambda$ in Fig. 3 .

\subsection{Underlying principles of solution-diffusion framework are applicable to TFC-PA aqueous separation membranes}

Fig. 4 shows the relationship between the two S-D transport elements, $\theta$ and $\lambda$, for the six solutes and water (data from Fig. 1, as summarized in Table 2). Because of the strong correlation between $\lambda$ and $\left(d_{\mathrm{s}} /\right.$ $\left.d_{\mathrm{w}}\right)^{2}-1$, the analysis is equivalent to examining the influence of solute molecular size on $\theta$ (Fig. D1 in Appendix). Linear regression of $\theta$ on $\lambda$ yielded excellent fit, with $R^{2}$ of 0.982 (red dashed line of Fig. 4). This result is consistent with the solution-diffusion theoretical framework. The first and second terms that constitute the transport element, $\theta=$ $(\lambda+1) \log \left(R T / \nu_{\mathrm{w}}\right)+\lambda \log (360 L)-\log \beta$, are explicitly dependent on $\lambda$. In the S-D framework for polymeric gas separation membranes, the permeability-selectivity fitting parameter $\beta$ can be modeled as (Freeman, 1999):

$\log \beta=\log e \times\left\{-\lambda\left[b-f\left(\frac{1-a}{R T}\right)-\ln K_{\mathrm{w}}\right]+\ln \left(\frac{K_{\mathrm{w}}}{K_{\mathrm{s}}}\right)\right\}$

where $a$ is a constant that describes diffusion transport, $b$ and $f$ are polymer-dependent variables, and $K_{\mathrm{W}}$ and $K_{\mathrm{s}}$ are sorption coefficients of water and solute in the polymer, respectively. Therefore, the vertical axis intercept of the $\theta-\lambda$ fitting is $\log \left(R T / \nu_{\mathrm{w}}\right)-\log e \times\left(K_{\mathrm{w}} / K_{\mathrm{s}}\right)$. In the S-D model for gas separation membranes, interactions between light gas permeants and the polymeric membrane are assumed to be negligible and polymer-dependent $b$ and $f$ are considered to be constant for the membrane. But as the chlorination treatment employed in this study modified physicochemical properties of the polyamide, $b$ and $f$ are likely to be altered. Additionally, as discussed above, the chlorination increases membrane hydrophilicity and solute sorption. Therefore, $K_{\mathrm{w}}$ and $K_{\mathrm{S}}$ are expected to change. However, the close proximity of the intercept (0.94) to $\log \left(R T / v_{\mathrm{w}}\right)=3.14$ (i.e., data point for $\mathrm{H}_{2} \mathrm{O}$ ), even though the six solutes have different $K_{\mathrm{s}}$, signifies that the intercept is dominated by the $\log \left(R T / v_{\mathrm{w}}\right)$ term and the contribution of the $\ln \left(K_{\mathrm{s}} / K_{\mathrm{w}}\right)$ term is comparatively small. Constraining the intercept to $\log \left(R T / v_{\mathrm{w}}\right)$ lowers the goodness of fit for the $\theta-\lambda$ linear regression (black dotted line, $R^{2}=0.845$ ), indicating that influences of polymer properties ( $b$ and $f$ ) and sorption coefficients $\left(K_{\mathrm{w}}\right.$ and $K_{\mathrm{s}}$ ) on $\beta$ and $\theta$, though relatively minor, are still non-negligible.

Importantly, the analyses of $\lambda$ and $\theta$ (Figs. 3 and 4, respectively) indicate that the theoretical framework of gas transport across dense polymeric membrane is also applicable to elucidate solution-diffusion transport of nonelectrolyte solutes in TFC-PA membranes for aqueous separations. This suggests that, knowing the molecular diameter, the permeability-selectivity behavior of a solute (i.e., $\lambda$ and $\theta$ ) can be $a$ priori predicted using membrane thickness $(L)$, polymer characteristics $(b$ and $f$ ), and permeant affinities for the polymer $\left(K_{\mathrm{w}}\right.$ and $\left.K_{\mathrm{s}}\right)$. Further, we note 
that the correlation between $\lambda$ and $\left(d_{\mathrm{s}} / d_{\mathrm{w}}\right)^{2}-1$ spans a substantially wider range of values (0.7-9.7) than typical penetrant pairs examined in gas separation membranes (around 0.1-1.2) (Freeman, 1999; Robeson et al., 2009), suggesting that the solution-diffusion mechanism is still adequately valid for describing the transport of permeant pairs with considerably greater size difference, i.e., water and small neutral organic molecules.

While $b$ is an established constant denoting glassy or rubbery polymers $\left(-\ln \left(10^{-5} \mathrm{~cm}^{2} / \mathrm{s}\right)\right.$ and $-\ln \left(10^{-4} \mathrm{~cm}^{2} / \mathrm{s}\right)$, respectively) (Freeman, 1999), the physical significance of $f$ in Eq. (10) is currently not fully understood beyond the general acceptance that it is polymer-dependent and is influenced by interchain spacing ( $f$ is typically determined by empirical fitting) (Freeman, 1999). Sorption coefficient, $K$, is defined as the concentration ratio of the component (water or solute) in the membrane polymer matrix to the bulk-phase solution. Although there are several studies to characterize $K$ using different experimental approaches (Chan et al., 2013; Dražević et al., 2014; Lee et al., 2013; Liu et al., 2009; Zhang et al., 2009), efforts thus far have yet to converge on a common agreement for water uptake and solute concentration profile in the selective layer of TFC-PA membranes. Thickness of the polyamide layer of TFC membranes, $L$, is typically characterized as $\approx 60-200 \mathrm{~nm}$ using various microscopy techniques (Lin et al., 2016a; Pacheco et al., 2010; Park et al., 2017; Petersen, 1993), but recent studies utilizing alternative methods suggest that the effective $L$ (sometimes termed the "dense layer") is much thinner, $10-20 \mathrm{~nm}$, than the whole polyamide layer (Culp et al., 2018; Freger, 2003; Fridman-Bishop and Freger, 2017; Lin et al., 2016b; Song et al., 2020; Yan et al., 2015). Further work is necessary to accurately determine polymer properties $f$ and $L$, and permeant-polymer interactions $K_{\mathrm{w}}$ and $K_{\mathrm{s}}$ to understand their influence on $\beta$.

\subsection{Data suggests transition between regimes is governed by solute size}

Elements of the transition and $A \approx \Perp B$ regime, $\sigma, \omega$ and $\kappa$, as a function of van der Waals diameter for the four larger solutes of $\mathrm{Er}, \mathrm{Xy}$, $\mathrm{Gl}$, and La are shown in Fig. 5A-C, respectively (the correlations as a function of minimal projection and Stokes diameters are presented in Fig. D2 in the Appendix). The water permeance coefficient demarcating the two transport regimes, $10^{\sigma}$, monotonically increases with molecular diameter (Fig. 5A). That is, the transition to solution-diffusion transport, as depicted in Fig. 2, shifts toward the right as solute size increase, extending the range of the additional transport regime. Linear regression of $10^{\sigma}$ on $d^{\mathrm{v}}$ for the four larger solutes, $\mathrm{Er}, \mathrm{Xy}, \mathrm{Gl}$, and La, yields excellent fit $\left(R^{2}=0.9996\right)$, suggesting that the boundary between the two regimes can be predicted using the solute van der Waals diameter. The other two diameters analyzed here gave linear regressions with equally good fits ( $R^{2}$ of 0.9997 and 0.9985 for the minimal projection and Stokes diameters, respectively, Figure D2A). Good correlation is also observed between $10^{\sigma}$ and the S-D element $\lambda\left(R^{2}=0.997\right.$, Figure D3A in the Appendix). Although the results here suggest that the boundary between the two transport regimes is determined by the solute size, we hesitate to draw any definitive conclusions on the principal factor governing the threshold $\sigma$ with data of only four solutes.

Using the van der Waals diameters of the two smaller solutes, the threshold water permeance coefficients, $10^{\sigma}$, calculated using the regression equation yielded negative values for $\mathrm{Eg}$ and $\operatorname{Tr}(-1.32$ and $-0.02 \mathrm{~L} \mathrm{~m}^{-2} \mathrm{~h}^{-1} \mathrm{bar}^{-1}$, respectively). That is, the correlation of Fig. 5A predicts that the smaller solutes of ethylene glycol and 1,3,5-trioxane should not have additional regimes, in agreement with the observed experimental results (Fig. 1). Alternatively, the horizontal intercept of the $10^{\sigma}-d^{\mathrm{v}}$ fitting, $5.32 \AA$, represents the minimal van der Waals diameter for a solute to exhibit the additional regime. However, both Eg and $\operatorname{Tr}$ possess smaller $d^{\mathrm{v}}$ of 4.92 and $5.31 \AA$, respectively. We further conjecture that the $10^{\sigma}-d^{\mathrm{v}}$ horizontal intercept of $5.32 \AA$ is of physical significance and is related to the structure of the hydrated polyamide selective layer. Specifically, this dimension is very similar to the diameter of the free volume elements of wet polyamide in TFC seawater RO membranes, $5.56 \AA$ (Lee et al., 2013), determined by positron annihilation lifetime spectroscopy (PALS), and is slightly larger than the dry state PALS characterizations of 4.46-5.18 ̊ (Fujioka et al., 2013; Fujioka et al., 2015; Shimazu et al., 2000). The horizontal intercepts of $10^{\sigma}-d^{\mathrm{v}}$ using minimal projection and Stokes diameters are 5.68 and 4.06 $\AA$, respectively (Fig. D2 in the Appendix).

\subsection{Analysis of transport characteristic elements in the $A \approx \Perp B$ regime}

Because the additional regime is observed in relatively narrow windows for only four of the six solutes, experimental data is limited and the $\log A-\log B$ trend is not readily apparent. As such, two alternative characteristic elements are examined: $\log B$ at the lowest measured water permeance coefficient, denoted by $\omega$ (transport in the region to $\sigma$ is considered as gradually shifting to the $\mathrm{S}$-D regime), or constant $\log B$ $\log A$ slope of $\kappa$. Fig. 5B shows a monotonic decrease in $\omega$ as the solute size increases, sharply declining from Er to La. This implies a mechanism of size-based selectivity of solute is present in the additional regime of the unmodified TFC-PA: the membrane is less permeable (i.e., lower $\omega$ ) to larger solutes. A linear relationship between $\omega$ and $d^{\mathrm{v}}$ is also observed $\left(R^{2}=0.824\right)$, suggesting that $\omega$ can potentially be predicted using the solute diameter, although further validation studies will be necessary. However, we note that the solute permeance coefficients at the lowest $A$, $10^{\omega}$, are very low, ranging from 0.0015 to $0.0028 \mathrm{~L} \mathrm{~m}^{-2} \mathrm{~h}^{-1}$ and, hence, inherently have relatively greater experimental variability (the signal of permeate concentration is less than 1 order of magnitude greater than the noise of the background TOC content), which confounds the precise identification of $\omega$.

The alternative analysis of $\log B-\log A$ slope, $\kappa$, as a function of the van der Waals diameter, $d^{\mathrm{v}}$ is presented in Fig. 5C. Overall, no clear trend relating $\kappa$ and $d^{\mathrm{v}}$ is observed. From the limited data, all four solutes exhibited $\kappa$ below 1 (i.e., slope for water), signifying that the membrane water permeability is increasing faster than the increase in solute permeability, which contradicts the general understanding of classic solution-diffusion transport (rise in $B$ is always greater than gains in $A$ ). We, thus, postulate a counter explanation: $\log B-\log A$ slopes in the additional regime are actually $\approx 1$. With the exception of Xy, $\kappa$ of the other solutes are relatively close to unity (within the constraint of limited data points); for La, which has the widest "additional regime" range, $\kappa$ is practically 1.0. In other words, solute and water transport in the additional regime change at the same rate. When $A$ increases beyond the threshold $\sigma$, transport transitions into the conventional S-D regime. Consequently, the $\log B-\log A$ slope, $\lambda+1$, ramps up to $>1$ and solute permeability increases faster than water permeability. Similar $\omega$ and $\kappa$ trends are observed for minimal projection diameter, Stokes diameter, and $\lambda$ (Figs. D2 and D3 in the Appendix). Because of the relatively narrow range of most of the additional regimes observed in this study and the experimental uncertainty arising from the permeate TOC concentrations being less than an order of magnitude greater than the background, we recommend additional investigations to further probe the behavior and trends of $\kappa$.

\section{Implications for further understanding transport mechanisms of TFC-PA membranes}

In the S-D framework for gas separation membranes, the diffusion of light gas molecules in the membrane polymer is modeled as an activated process, with activation energy of the gas penetrant proportional to the square of molecular diameter (Brandt, 1959; Freeman, 1999; Sanders et al., 2013; Teplyakov and Meares, 1990). This study finds that, in aqueous separations, the $\mathrm{S}$-D element, $\lambda$, exhibits good agreement with the predictive term, $\left(d_{\mathrm{s}} / d_{\mathrm{w}}\right)^{2}-1$, which is derived from classic diffusion theory. This strong correlation suggests that the relationship between activation energy and penetrant property in the activated diffusion model is also likely applicable to the transport of water and neutral 
molecules in TFC-PA membranes. Under the transport framework of activated diffusion in gas separation membranes, $\ln D \propto-c d^{2}$ : permeant diffusivity is negatively correlated to the molecular size but increases as the polymer chains become more flexible and polymer-related parameter $c$ decreases (Brandt, 1959; Freeman, 1999). We postulate that the principles are also valid for aqueous separation membranes. Increasing membrane permeability by reducing polymer chain stiffness, i.e., lower $c$, yields steeper tradeoff slopes, $\lambda_{\mathrm{w} / \mathrm{s}}$, for solutes of larger molecular diameter (detailed discussion in Appendix A), as observed for the six solutes investigated in this study. Additional studies can elucidate the role of activated diffusion in transport for aqueous separation membranes. Similarly, while this study analyzed the relationships of $\lambda$ with van der Waals diameter, minimal projection diameter, and Stokes diameter, further investigations are necessary to concisely pinpoint the most appropriate molecular dimension to represent the penetrant size. Examining an expanded range of nonelectrolyte solutes with different chemical structures, beyond the six investigated here, can improve understanding on the role of moiety-specific interactions in transport. Likewise, additional studies on the transport of electrolyte and ionic solutes across aqueous separation membranes can shed light on the role of other mechanisms, such as charge and dielectric effects.

The other transport element in the S-D regime, $\beta$, is influenced by polymer properties of the selective layer. Advancing the characterization of $\beta$ requires systematic understanding of the aromatic polyamide polymer, specifically, the interchain spacing parameter, $f$. Analogous to the plasticization of polymeric membrane materials by gas penetrants (Bernier and Kambour, 1968; Bos et al., 1999; Hiemenz and Lodge, 2007; Sanders, 1988), the impacts of water hydration on TFC-PA membrane properties, i.e., $b$ and $f$, in aqueous separations are worth deeper examination. The potential influence of other membrane properties, e.g., functional groups and fixed charge density, and solute chemical parameters, such as, octanol water partition coefficient, on the permeability-selectivity tradeoff should also be evaluated. A cohesive theoretical framework relating transport to permeant properties and selective layer structure and chemistry will enable accurate $a$ priori prediction of the rejection of current and emerging contaminants in RO and NF.

The S-D model indicates that $\lambda$ is independent of selective layer properties, i.e., for a certain solute, the slope of the $\log B-\log A$ profile remains unchanged regardless of selective layer chemistry. Instead, membrane selectivities can be rationally enhanced by lowering $\theta$. This can be achieved by altering the selective layer chemistry to increase $\beta$, which is a function of $f$ and $K$ (Eq. (10)). Enlarging the polymer interchain spacing can lead to a greater $f$, as shown in previous studies that demonstrated the influence of PA selective layer crosslinking densities on transport across the membrane (Ghosh et al., 2008; Song et al., 2005; Soroush et al., 2012; Wu et al., 1997). Water sorption (partitioning) coefficient, $K_{\mathrm{w}}$, can also be raised through increasing hydrophilicity of the selective layer polymer.

Improving solute selectivity has been identified as a more critical focus for aqueous separation membranes than raising water permeability (Werber et al., 2016a). Results of this study indicate that solute permeability is relatively independent of or only weakly related to water permeability in the $A \approx \Perp B$ regime, a feature that can be exploited to optimize the balance between permeability and selectivity. For separations requiring high rejection of a specific solute, membranes with water permeability just below the threshold $\sigma$ should be utilized, i.e., operate in the $A \approx \Perp B$ regime just before the transition to the $S$-D regime, to achieve high water permeability without drastic sacrifice in selectivity. Precise determination of $\sigma$ is, therefore, important, and further investigations with a wider range of solutes are necessary to establish the principal factors governing $\sigma$. Thorough characterization and analysis can reveal the impacts of selective layer structural properties on $\omega$ and $\kappa$. Crucially, further work is needed to shed light on the genesis of the additional regime.

\section{Conclusion}

This study introduces a framework for better understanding of the transport phenomena in TFC-PA membranes for aqueous separations. The transport of nonelectrolyte solutes with different sizes across TFCPA membranes with a range of permeabilities and selectivities was examined. Tradeoff between water permeability and solute selectivity was observed for all six solutes, with the slopes of the tradeoff lines, $\lambda$, relate to the solute and solvent (i.e., water) diameters, $d_{\mathrm{s}}$ and $d_{\mathrm{w}}$, respectively, by $\lambda=\left(d_{\mathrm{s}} / d_{\mathrm{w}}\right)^{2}-1$, consistent with the S-D framework. The intercepts of the tradeoff lines were also shown to be related to $d_{s}$. Additionally, a second transport regime that cannot be fully explained by the classic S-D model is observed under the experimental conditions of the study. Further characterization indicates that the transition between the two transport regimes is affected by the solute size. Importantly, solute permeability in this regime is relatively independent of or only weakly related to water permeability. A set of transport characteristic elements that describes the water permeability-solute selectivity relationship is proposed and elements are shown to be principally dependent on solute size. Further, we put forth the notion that this unique set of transport characteristic elements can be determined for nonelectrolyte solutes to predict the permeability-selectivity transport trend of the solute. Findings of this study can provide important insights for the development of next-generation membrane materials with enhanced selectivity and enable accurate a priori prediction of the contamination rejection.

\section{Declaration of competing interest}

None

\section{Acknowledgments}

We acknowledge the helpful comments and suggestions of the anonymous reviewers in examining the rigor of the study and sharpening the discussions.

\section{Appendix A. Solution-diffusion transport theory}

Development of the solution-diffusion (S-D) framework for pressure-driven osmotic processes can be found in literature (Baker, 2012; Geise et al., 2011; Paul, 2004; Wijmans and Baker, 1995); the principal equations are presented here for ease of reference. Concentration profiles of the solvent (water) and solute in a pressure-driven osmotic membrane process, i.e., reverse osmosis and nanofiltration, are shown in Fig. A1. In S-D, the integrated mass flux of component $i$ across the membrane selective layer is $J_{i}=D_{i}\left(c_{i, \mathrm{~F}}^{\mathrm{m}}-c_{i, \mathrm{P}}^{\mathrm{m}}\right) / L$, where $D_{i}$ is the diffusion coefficient, $L$ is the membrane selective layer thickness, and $c_{i, \mathrm{~F}}^{\mathrm{m}}$ and $c_{i, \mathrm{P}}^{\mathrm{m}}$ are membrane-phase concentrations (signified by superscript $\mathrm{m}$ ) of the component at the feed and permeate side, respectively (subscripts F and P). Factoring in the hydraulic pressure of the feed, membrane, and permeate phases and accounting for osmotic pressure of the feed and permeate streams yield the water and solute fluxes, $J_{\mathrm{w}}$ and $J_{\mathrm{s}}$ :

$J_{\mathrm{w}}=\frac{D_{\mathrm{w}} c_{\mathrm{w}, \mathrm{F}}^{\mathrm{m}}}{L} \frac{v_{\mathrm{w}}{ }^{2}}{R T}(\Delta P-\Delta \pi)$ 


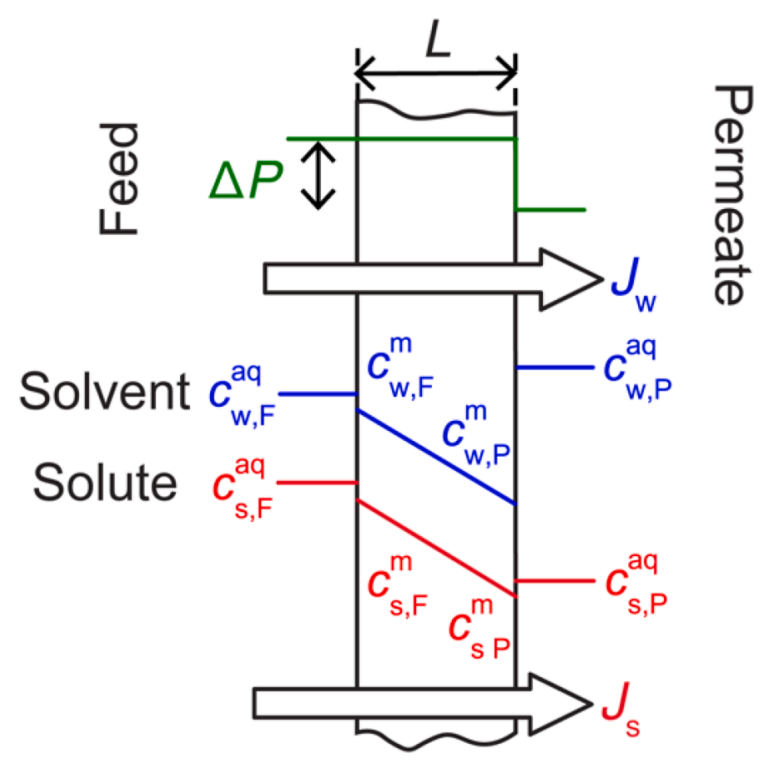

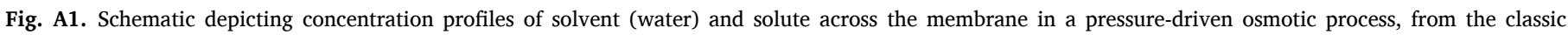
solution-diffusion perspective. The feed and membrane phases are pressurized at $\Delta P$, while the permeate phase is not pressurized.

$J_{\mathrm{s}}=\frac{D_{\mathrm{s}}}{L}\left(c_{\mathrm{s}, \mathrm{F}}^{\mathrm{m}}-c_{\mathrm{s}, \mathrm{P}}^{\mathrm{m}}\right)$

where $\Delta P$ is the applied hydraulic pressure difference, $\Delta \pi$ is the osmotic pressure difference across the membrane, and $v_{\mathrm{w}}$ is the molar volume of water. Note that an additional $v_{\mathrm{w}}$ is introduced in Eq. (A1) to convert the units of $J_{\mathrm{w}}$ from molar to volumetric flux. Subscripts "w" and "s" denote component water and solute, respectively.

Sorption coefficient, $K_{i}$, of component $i$ is defined as the ratio of the interfacial concentration in the membrane to aqueous phase (denoted by superscripts "m" and "aq") and is expressed as $K_{\mathrm{w}}=c_{\mathrm{w}, \mathrm{F}}^{\mathrm{m}} / c_{\mathrm{w}, \mathrm{F}}^{\mathrm{aq}} \approx c_{\mathrm{w}, \mathrm{F}}^{\mathrm{m}} \times v_{\mathrm{w}}$ and $K_{\mathrm{s}}=c_{\mathrm{s}, \mathrm{F}}^{\mathrm{m}} / c_{\mathrm{s}, \mathrm{P}}^{\mathrm{aq}}$ for water and solute, respectively. Permeability of $i$ is $P_{i}=K_{i} D_{i}$, i.e., product of the solution and diffusion components of S-D. Substituting these terms into Eqs. (A3) and (A4) yields:

$J_{\mathrm{w}}=\frac{D_{\mathrm{w}} K_{\mathrm{w}}}{L v_{\mathrm{w}}} \frac{v_{\mathrm{w}}^{2}}{R T}(\Delta P-\Delta \pi)=\frac{P_{\mathrm{w}}}{L} \frac{v_{\mathrm{w}}}{R T}(\Delta P-\Delta \pi)$

$J_{\mathrm{s}}=\frac{D_{\mathrm{s}} K_{\mathrm{s}}}{L}\left(c_{\mathrm{s}, \mathrm{F}}^{\mathrm{aq}}-c_{\mathrm{s}, \mathrm{P}}^{\mathrm{aq}}\right)=\frac{P_{\mathrm{s}}}{L}\left(c_{\mathrm{s}, \mathrm{F}}^{\mathrm{aq}}-c_{\mathrm{s}, \mathrm{P}}^{\mathrm{aq}}\right)$

Water and solute fluxes in aqueous separations are commonly expressed with phenomenological permeance coefficients, $A$ and $B$, as $J_{\mathrm{w}}=A(\Delta P-\Delta \pi)$ and $J_{\mathrm{s}}=B\left(c_{\mathrm{s}, \mathrm{F}}^{\mathrm{aq}}-c_{\mathrm{s}, \mathrm{P}}^{\mathrm{aq}}\right)$, respectively. Eqs. (3) and (4) in the main manuscript can be obtained by equating the phenomenological flux equations with Eqs. (A3) and (A4):

$A=\frac{P_{\mathrm{w}}}{L} \frac{v_{\mathrm{w}}}{R T}$

$B=\frac{P_{\mathrm{s}}}{L}$

The solution-diffusion model for gas separations is briefly presented here; detailed discussions can be found in literature (Baker, 2012; Freeman, 1999; Wijmans and Baker, 1995). In the solution-diffusion framework, the membrane selectivity of gas A over gas B can resolved into the ratios of sorption coefficients and diffusivities as $\alpha_{\mathrm{A} / \mathrm{B}} \equiv P_{\mathrm{A}} / P_{\mathrm{B}}=\left(K_{\mathrm{A}} / K_{\mathrm{B}}\right) \times\left(D_{\mathrm{A}} / D_{\mathrm{B}}\right)$. Diffusive transport across the membrane in gas separation is described by the activation energy model, with diffusivity proportional to the square of the gas molecule kinetic diameter. The logarithm of the selectivity can, thus, be expressed as (Freeman, 1999; Teplyakov and Meares, 1990):

$\ln \alpha_{\mathrm{A} / \mathrm{B}}=\ln \left(\frac{K_{\mathrm{A}}}{K_{\mathrm{B}}}\right)+\left(\frac{1-a}{R T}\right) c\left(d_{\mathrm{B}}^{2}-d_{\mathrm{A}}^{2}\right)$

where $a$ is an independent constant, $c$ is a polymer-dependent variable, and $d$ is the gas molecule kinetic diameter. Applying the principles of activated diffusion to the permeability, $P_{i}=K_{i} D_{i}$, gives:

$\ln P_{\mathrm{A}}=-\left(\frac{1-a}{R T}\right) c d_{\mathrm{A}}^{2}+f\left(\frac{1-a}{R T}\right)-b+\ln K_{\mathrm{A}}$

The empirical permeability-selectivity tradeoff relationship is described by $P_{\mathrm{A}} / P_{\mathrm{B}}=\beta / P_{\mathrm{A}}{ }^{\lambda}$ (equivalent to Eq. (5) of the main manuscript), where $\lambda$ and $\beta$ are fitting parameters. Combining Eqs. (A5) and (A6), and rearranging the terms yields (Freeman, 1999): 
$\ln \alpha_{\mathrm{A} / \mathrm{B}}=-\left[\left(\frac{d_{\mathrm{B}}}{d_{\mathrm{A}}}\right)^{2}-1\right] \ln P_{\mathrm{A}}+\left\{\ln \left(\frac{K_{\mathrm{A}}}{K_{\mathrm{B}}}\right)-\left[\left(\frac{d_{\mathrm{B}}}{d_{\mathrm{A}}}\right)^{2}-1\right]\left[b-f\left(\frac{1-a}{R T}\right)-\ln K_{\mathrm{A}}\right]\right\}$

Correspondingly, expressions for the fitting parameters $\lambda$ and $\beta$ can be obtained by comparing Eq. (A7) with the logarithmic of the tradeoff rela-

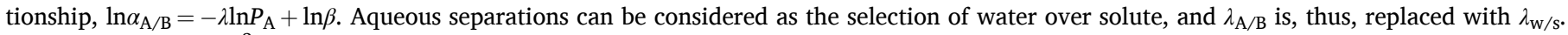
Therefore, $\lambda=\left(d_{\mathrm{s}} / d_{\mathrm{w}}\right)^{2}-1$, and $\log \beta$ is (Eq. (10) in the main manuscript):

$\log \beta=\log e \times\left\{-\lambda\left[b-f\left(\frac{1-a}{R T}\right)-\ln K_{\mathrm{w}}\right]+\ln \left(\frac{K_{\mathrm{w}}}{K_{\mathrm{s}}}\right)\right\}$

The dependence of the tradeoff slope, $\lambda_{\mathrm{w} / \mathrm{s}}$, on solute molecular diameter can similarly be examined by analyzing the separation of gases A and B. Under the activated diffusion framework, polymer parameter $c$ describes the chain mobility, with permeant transport related to $c$ by the relation $\ln D \propto$ $-c$ (Brandt, 1959; Freeman, 1999): as chain mobility increases, $c$ decreases and the membrane is more permeable. Because $\lambda_{\mathrm{A} / \mathrm{B}}$ is the negative slope of the logarithm of the selectivity, $\alpha_{\mathrm{A} / \mathrm{B}} \equiv P_{\mathrm{A}} / P_{\mathrm{B}}$, with respect to the logarithm of the permeability for gas A, $P_{\mathrm{A}}$, i.e., $\lambda_{\mathrm{A} / \mathrm{B}}=\partial\left[\ln \left(P_{\mathrm{B}} / P_{\mathrm{A}}\right)\right] / \partial\left(\ln P_{\mathrm{A}}\right)$, and the logarithm of the membrane permeability scales with $-c, \lambda_{\mathrm{A} / \mathrm{B}}$ can therefore be qualitatively represented by

$-\frac{\partial\left[\ln \left(P_{\mathrm{B}} / P_{\mathrm{A}}\right)\right]}{\partial c}=\left(\frac{1-a}{R T}\right)\left(d_{\mathrm{B}}^{2}-d_{\mathrm{A}}^{2}\right)$

The dependence of $\lambda$ on the molecular diameter of gas $\mathrm{B}, \partial \lambda_{\mathrm{A} / \mathrm{B}} / \partial d_{\mathrm{B}}$, is, thus, equivalent to

$\frac{\partial\left\{-\partial\left[\ln \left(P_{\mathrm{B}} / P_{\mathrm{A}}\right)\right] / \partial c\right\}}{\partial d_{\mathrm{B}}}=2\left(\frac{1-a}{R T}\right) d_{\mathrm{B}}$

Using the universal value of $a=0.64$ (Freeman, 1999), the term $2(1-a) d_{\mathrm{B}} / R T$ is always positive. This indicates that in the separation of another gas (B) from gas A, the tradeoff slope is steeper for gases with larger molecular diameter. Extending the concept to aqueous separations, where water corresponds to gas A and the neutral solute is gas B, the slope of the permeability-selectivity tradeoff lines, $\lambda_{\mathrm{w} / \mathrm{s}}$, would also increase with larger solute size, as observed in this study.

\section{Appendix B. Analysis of convective transport relative to solution-diffusion transport}

The relative contribution of convective transport to overall transport can be analyzed using the Kedem-Katchalsky equation, where the total solute flux $\left(J_{\mathrm{S}}\right)$ is the sum of fluxes driven by solution-diffusion $\left(J_{\mathrm{s}}^{\mathrm{SD}}\right)$ and convection $\left(J_{\mathrm{s}}^{\mathrm{cv}}\right)($ Kargol, 2000):

$J_{\mathrm{s}}=J_{\mathrm{s}}^{\mathrm{SD}}+J_{\mathrm{s}}^{\mathrm{cv}}=B\left(c_{\mathrm{s}, \mathrm{F}}^{\mathrm{aq}}-c_{\mathrm{s}, \mathrm{P}}^{\mathrm{aq}}\right)+(1-\varsigma) J_{\mathrm{w}}\left\langle c_{\mathrm{s}, \mathrm{m}}^{\mathrm{aq}}\right\rangle$

here $\varsigma$ is the reflection coefficient, and $\left\langle c_{\mathrm{s}, \mathrm{m}}^{\mathrm{aq}}\right\rangle$ is the average concentration within the membrane matrix. A widely accepted simplification assumes a linear concentration profile inside the membrane, giving $\left\langle c_{\mathrm{s}, \mathrm{m}}^{\mathrm{aq}}\right\rangle=\left(c_{\mathrm{s}, \mathrm{F}}^{\mathrm{aq}}+c_{\mathrm{s}, \mathrm{P}}^{\mathrm{aq}}\right) / 2$ (Kargol, 2000; Surawanvijit et al., 2016). Rearranging Eq. (B1) yields:

$\frac{J_{\mathrm{w}} c_{\mathrm{s}, \mathrm{P}}^{\mathrm{aq}}}{c_{\mathrm{s}, \mathrm{F}}^{\mathrm{aq}}-c_{\mathrm{s}, \mathrm{P}}^{\mathrm{aq}}}=\frac{J_{\mathrm{w}}}{2}\left(\frac{c_{\mathrm{s}, \mathrm{F}}^{\mathrm{aq}}+c_{\mathrm{s}, \mathrm{P}}^{\mathrm{aq}}}{c_{\mathrm{s}, \mathrm{F}}^{\mathrm{aq}}-c_{\mathrm{s}, \mathrm{P}}^{\mathrm{aq}}}\right)(1-\varsigma)+B$

Defining $Y=J_{\mathrm{w}} c_{\mathrm{s}, \mathrm{P}}^{\mathrm{aq}} /\left(c_{\mathrm{s}, \mathrm{F}}^{\mathrm{aq}}-c_{\mathrm{s}, \mathrm{P}}^{\mathrm{aq}}\right)$ and $X=J_{\mathrm{w}}\left(c_{\mathrm{s}, \mathrm{F}}^{\mathrm{aq}}+c_{\mathrm{s}, \mathrm{P}}^{\mathrm{aq}}\right) /\left[2\left(c_{\mathrm{s}, \mathrm{F}}^{\mathrm{aq}}-c_{\mathrm{s}, \mathrm{P}}^{\mathrm{aq}}\right)\right]$, the coefficient $1-\varsigma$ is, thus, the slope of the linear regression of $Y$ on $X$.

To assess the largest possible contribution of convective transport, membranes with the greatest water permeance coefficients in the study ( $A=10.04 \pm 0.25 \mathrm{~L} \mathrm{~m}^{-2} \mathrm{~h}^{-1} \mathrm{bar}^{-1}$ ) were employed for this analysis. Terms $Y$ and $X$ of Fig. B1 were calculated from the water flux and concentration
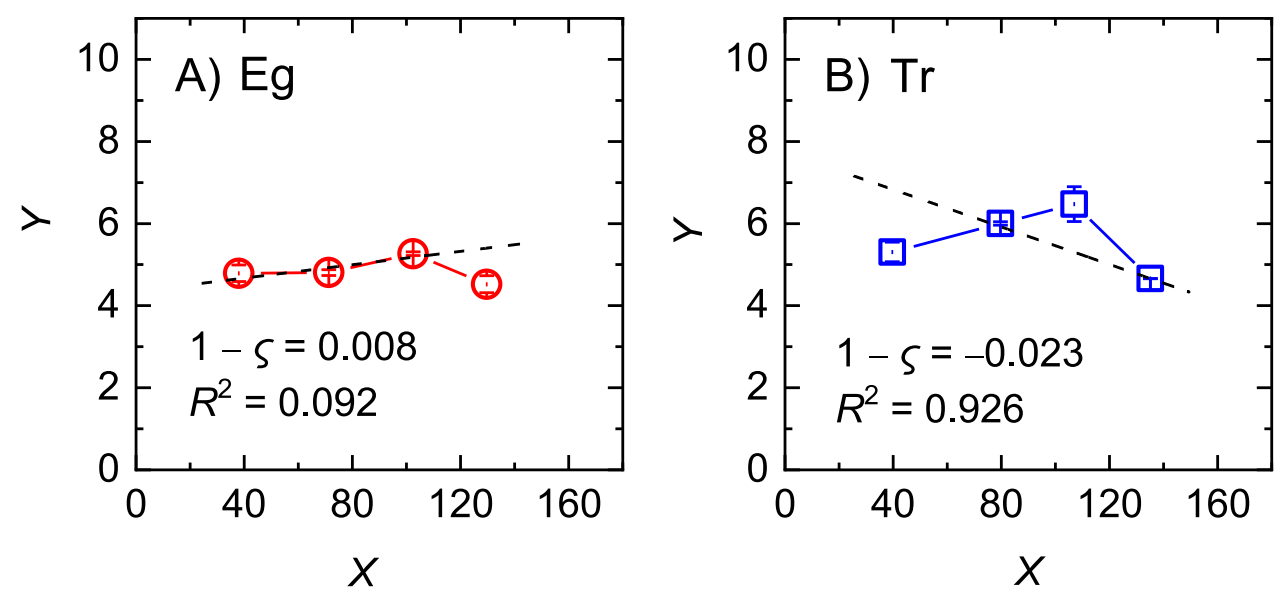

Fig. B1. $Y=J_{\mathrm{w}} c_{\mathrm{s}, \mathrm{P}}^{\mathrm{aq}} /\left(c_{\mathrm{s}, \mathrm{F}}^{\mathrm{aq}}-c_{\mathrm{s}, \mathrm{P}}^{\mathrm{aq}}\right)$ as a function of $X=J_{\mathrm{w}}\left(c_{\mathrm{s}, \mathrm{F}}^{\mathrm{aq}}+c_{\mathrm{s}, \mathrm{P}}^{\mathrm{aq}}\right) /\left[2\left(c_{\mathrm{s}, \mathrm{F}}^{\mathrm{aq}}-c_{\mathrm{s}, \mathrm{P}}^{\mathrm{aq}}\right)\right]$ for the permeation of nonelectrolyte solutes A) ethylene glycol, Eg, B) and trioxane, $\mathrm{Tr}$, across membranes with water permeance coefficient, $\mathrm{A}=10.04 \pm 0.25 \mathrm{~L} \mathrm{~m}^{-2} \mathrm{~h}^{-1} \mathrm{bar}^{-1}$. Slopes, $1-\varsigma$, and coefficients of determination, $R^{2}$, of the dashed linear regression lines are indicated in the plots. 
data of organic solutes ethylene glycol (Eg) and trioxane (Tr) under different operating pressures, $\Delta P$, of 6.9, 13.8, 20.7, and 27.6 bar (100, 200, 300, and $400 \mathrm{psi}$, respectively). $J_{\mathrm{w}}$ and $c_{\mathrm{s}, \mathrm{P}}^{\mathrm{aq}}$ were characterized using the same methods as described in the main manuscript and $c_{\mathrm{s}, \mathrm{F}}^{\mathrm{aq}}=J_{\mathrm{w}} / B+c_{\mathrm{s}, \mathrm{P}}^{\mathrm{aq}}=$ $c_{\mathrm{s}, \mathrm{P}}^{\mathrm{aq}}\left(J_{\mathrm{w}} / B+1\right)$. Fitting the data gives $|1-\varsigma|<0.023(1-\varsigma$ being slightly negative for $\mathrm{Tr}$ is likely due to limitations in accuracy of experimental measurements), with convection accounting for $<3.8 \%$ of total transport for Eg and Tr. Effectively, the slopes are horizontal or only slightly positive, i. e., $1-\varsigma \approx 0$. This result is in agreement with previous work that reported $1-\varsigma<0.003$ for TFC-PA membranes with $A$ of $4.8-5.5 \mathrm{~L} \mathrm{~m}^{-2} \mathrm{~h}^{-1}$ bar $^{-1}$ (Surawanvijit et al., 2016). Therefore, for membranes with the range of permeabilities and selectivities investigated in this study, the contribution of convection to total transport is very marginal and the solution-diffusion can be considered to be the primary transport phenomena.

\section{Appendix C. Transport characteristic elements and physicochemical properties of the solvent and solutes}

Water permeance coefficient, $A$, describes the transport of water in osmotic processes (Eq. (1) of the main manuscript). The driving force can be a transmembrane pressure difference, i.e., reverse osmosis, or a concentration gradient, i.e., conventional osmosis (or forward osmosis). In the absence of hydraulic pressurization in conventional osmosis, the water permeance can be equivalently converted to the solute permeance coefficient, $B$ (Eq. (2) of the main manuscript), except the permeant in this specific case is solvent instead of solute. Permeance coefficients for the solvent, water, under the two scenarios, $A$ and $B_{\mathrm{w}}$, can be related by equating the permeabilities, $P_{\mathrm{w}}=P_{\mathrm{s}}$ (Eqs. (3) and ((4)):

$B_{\mathrm{w}}=\frac{R T}{v_{\mathrm{w}}} A$

Rearranged to $\log B_{\mathrm{w}}=\log A+\log \left(R T / v_{\mathrm{w}}\right)$, the slope is, thus, $\lambda+1=1(\lambda=0$ as the membrane is not selective between solvent and the solute, which are both water in this analysis), and the vertical intercept, $\theta$, is $\log \left(R T / v_{\mathrm{w}}\right)=3.14 \log \beta$ is thus 0 , giving $\beta=1$.

\section{Appendix D. Supplementary data}

Tables D1 and D2

Table D1

Summary of chlorine-alkaline reaction conditions on membrane polyamide layers and the resultant water permeance coefficients. Alkaline immersion involves soaking the post-chlorine-treated membranes in $0.1 \mathrm{M} \mathrm{NaOH}$ for $16 \mathrm{~h}$. Multiple samples were treated under each reaction condition.

\begin{tabular}{|c|c|c|c|c|}
\hline$\#$ & NaOCl Concentration (ppm) & Treatment Duration (h) & Alkaline Immersion & $\begin{array}{l}\text { Water Permeance Coefficient, } \\
A\left(\mathrm{~L} \mathrm{~m}^{-2} \mathrm{~h}^{-1} \mathrm{bar}^{-1}\right)\end{array}$ \\
\hline $1 *$ & 0 & 0 & No & $0.86 \pm 0.03$ \\
\hline $2^{*}$ & 0 & 0 & No & $1.30 \pm 0.16$ \\
\hline 3 & 0 & 0 & Yes & $2.32 \pm 0.02$ \\
\hline 4 & 100 & 1 & Yes & $2.78 \pm 0.33$ \\
\hline 5 & 200 & 1 & Yes & $2.93 \pm 0.38$ \\
\hline 6 & 1,500 & 1 & Yes & $5.06 \pm 1.89$ \\
\hline 7 & 3,000 & 1 & Yes & $8.45 \pm 4.21$ \\
\hline 8 & 8,000 & 1 & Yes & $9.52 \pm 5.16$ \\
\hline 9 & 10,000 & 1 & Yes & $11.98 \pm 4.42$ \\
\hline 10 & 10,000 & 2 & Yes & $13.15 \pm 2.81$ \\
\hline
\end{tabular}

* Samples No. 1 and No. 2-11 are from two different membrane rolls of the same product. Hence, unmodified Samples No. 1 and 2 have dissimilar $A$.

Table D2

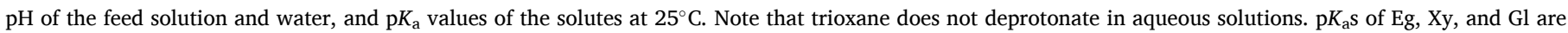
obtained from references (Lide, 2004) and Er and La are analyzed using MarvinSketch software (MarvinSketch).

\begin{tabular}{|c|c|c|c|}
\hline Solute & Abbreviation & Feed Solution $\mathrm{pH}$ & $\mathrm{p} K_{\mathrm{a}}$ \\
\hline Water & N/A & $5.76 \pm 0.06$ & 14.00 \\
\hline Ethylene glycol & $\mathrm{Eg}$ & $5.87 \pm 0.18$ & 15.10 \\
\hline Trioxane & $\operatorname{Tr}$ & $6.23 \pm 0.37$ & N/A \\
\hline Erythritol & $\mathrm{Er}$ & $5.97 \pm 0.32$ & 13.04 \\
\hline Xylose & $\mathrm{Xy}$ & $5.93 \pm 0.41$ & 12.14 \\
\hline Glucose & $\mathrm{Gl}$ & $5.87 \pm 0.06$ & 12.46 \\
\hline Lactose & $\mathrm{La}$ & $5.85 \pm 0.12$ & 11.25 \\
\hline
\end{tabular}



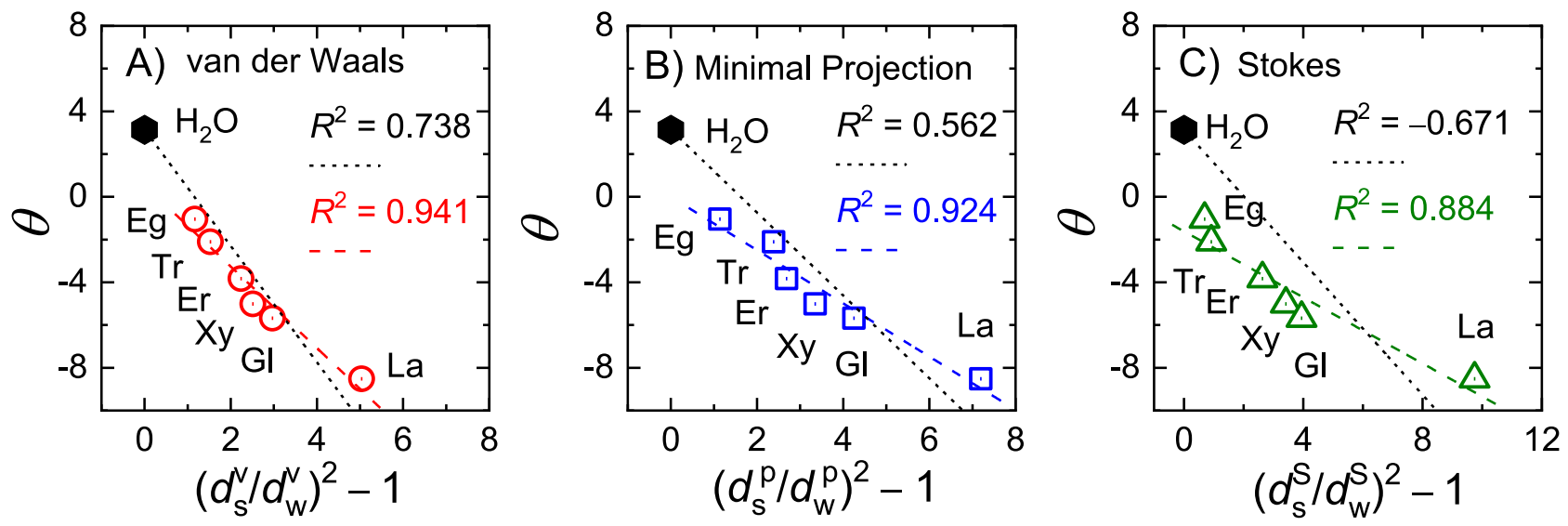

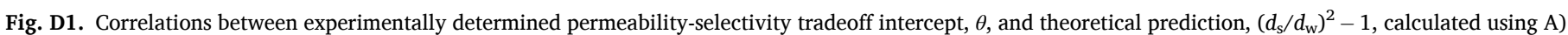

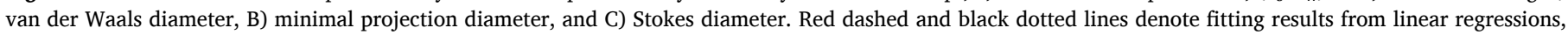
without fixed intercept and with fixed intercept of $\log \left(R T / v_{\mathrm{w}}\right)$, respectively.
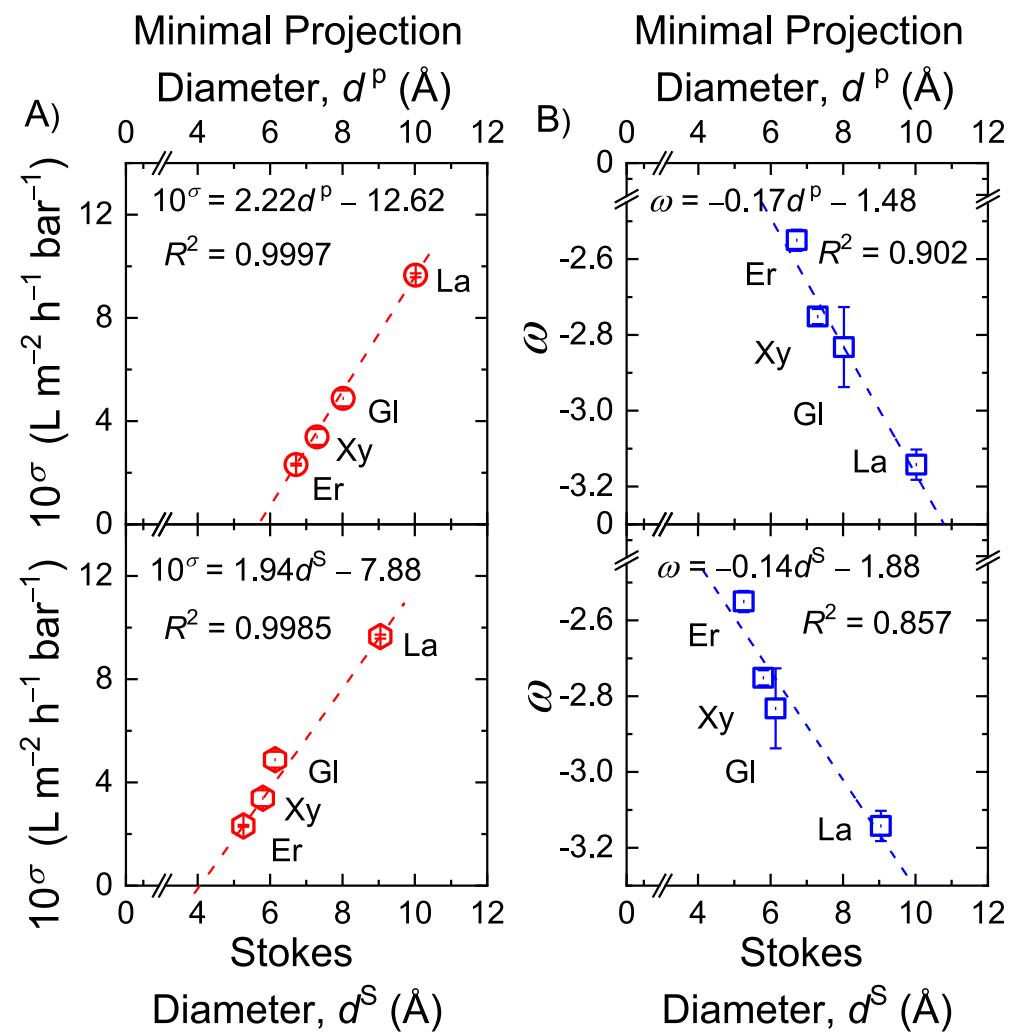

\section{Minimal Projection \\ Diameter, $d^{\mathrm{P}}(\AA)$}

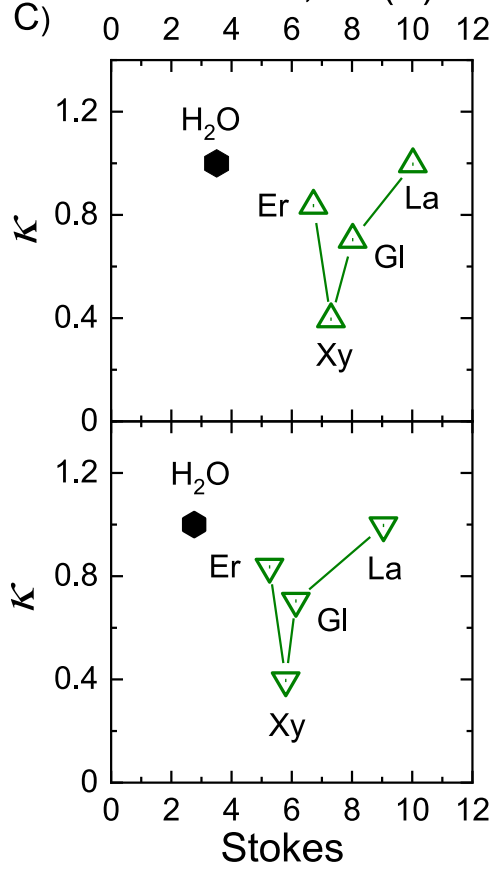

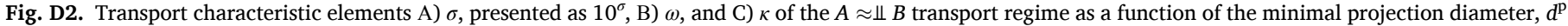
(upper panels), and the Stokes diameter, $d^{S}$ (lower panels), for the four larger solutes of erythritol (Er), D-xylose (Xy), $\alpha$-glucose (Gl), and $\alpha$-lactose (La). 

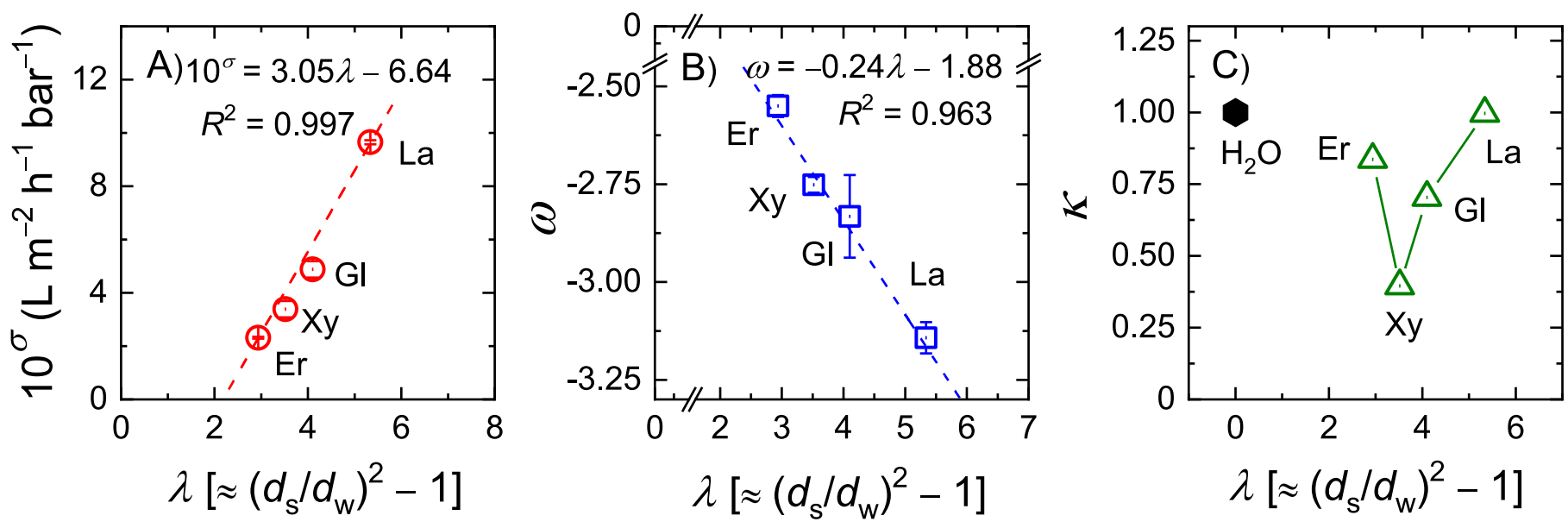

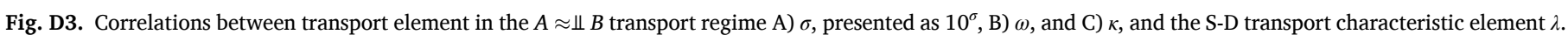

\section{References}

Anslyn, E.V., Dougherty, D.A., 2006. Modern physical organic chemistry. University science books.

Baker, R.W., 2012. Membrane technology and applications. John Wiley \& Sons, Chichester, West Sussex; Hoboken.

Baker, R.W., Low, B.T., 2014. Gas separation membrane materials: a perspective. Macromolecules 47 (20), 6999-7013.

Bartholomew, T.V., Mey, L., Arena, J.T., Siefert, N.S., Mauter, M.S., 2017. Osmotically assisted reverse osmosis for high salinity brine treatment. Desalination 421, 3-11.

Batsanov, S.S., 2001. Van der Waals radii of elements. Inorg. Mater. 37 (9), 871-885.

Bellona, C., Drewes, J.E., Xu, P., Amy, G., 2004. Factors affecting the rejection of organic solutes during NF/RO treatment-a literature review. Water Res 38 (12), 2795-2809.

Bernier, G.A., Kambour, R.P., 1968. The Role of Organic Agents in the Stress Crazing and Cracking of Poly(2,6-dimethyl-1,4-phenylene oixde). Macromolecules 1 (5), 393-400.

Bird, R.B., Stewart, W.E., Lightfoot, E.N., 2007. Transport phenomena. John Wiley \& Sons.

Bolong, N., Ismail, A.F., Salim, M.R., Matsuura, T., 2009. A review of the effects of emerging contaminants in wastewater and options for their removal. Desalination 239 (1-3), 229-246.

Bonner, O.D., Breazeale, W.H., 1965. Osmotic and Activity Coefficients of Some Nonelectrolytes. J. Chem. Eng. Data 10 (4), 325-327.

Bos, A., Pünt, I.G.M., Wessling, M., Strathmann, H, 1999. CO2-induced plasticization phenomena in glassy polymers. J. Membr. Sci. 155 (1), 67-78.

Bowen, W.R., Welfoot, J.S., 2002. Modelling the performance of membrane nanofiltration—critical assessment and model development. Chem. Eng. Sci. 57 (7), $1121-1137$.

Brandt, W.W., 1959. Model calculation of the temperature dependence of small molecule diffusion in high polymers. J. Phys. Chem. 63 (7), 1080-1085.

Breitner, L.N., Howe, K.J., Minakata, D., 2019. Effect of Functional Chemistry on the Rejection of Low-Molecular Weight Neutral Organics through Reverse Osmosis Membranes for Potable Reuse. Environmental Science \& Technology 53 (19), 11401-11409.

Carçabal, P., Jockusch, R.A., Hünig, I., Snoek, L.C., Kroemer, R.T., Davis, B.G., Gamblin, D.P., Compagnon, I., Oomens, J., Simons, J.P., 2005. Hydrogen bonding and cooperativity in isolated and hydrated sugars: mannose, galactose, glucose, and lactose. J. Am. Chem. Soc. 127 (32), 11414-11425.

Chan, E.P., Young, A.P., Lee, J.H., Chung, J.Y., Stafford, C.M., 2013. Swelling of ultrathin crosslinked polyamide water desalination membranes. Journal of Polymer Science Part B: Polymer Physics 51 (6), 385-391.

Chen, X., Boo, C., Yip, N.Y., 2020. Transport and structural properties of osmotic membranes in high-salinity desalination using cascading osmotically mediated reverse osmosis. Desalination 479, 114335.

Comerton, A.M., Andrews, R.C., Bagley, D.M., Hao, C., 2008. The rejection of endocrine disrupting and pharmaceutically active compounds by NF and RO membranes as a function of compound and water matrix properties. Journal of Membrane Science 313 (1), 323-335.

Culp, T.E., Shen, Y.-X., Geitner, M., Paul, M., Roy, A., Behr, M.J., Rosenberg, S., Gu, J., Kumar, M., Gomez, E.D., 2018. Electron tomography reveals details of the internal microstructure of desalination membranes. Proc. Natl. Acad. Sci. U.S.A. 115 (35), 8694-8699.

Doederer, K., Farré, M.J., Pidou, M., Weinberg, H.S., Gernjak, W., 2014. Rejection of disinfection by-products by RO and NF membranes: Influence of solute properties and operational parameters. Journal of Membrane Science 467, 195-205.

Dražević, E., Košutić, K., Freger, V., 2014. Permeability and selectivity of reverse osmosis membranes: Correlation to swelling revisited. Water Res 49, 444-452.
Dražević, E., Košutić, K., Svalina, M., Catalano, J., 2017. Permeability of uncharged organic molecules in reverse osmosis desalination membranes. Water Res 116, 13-22.

Elimelech, M., Phillip, W.A., 2011. The future of seawater desalination: energy, technology, and the environment. science 333 (6043), 712-717.

Epsztein, R., DuChanois, R.M., Ritt, C.L., Noy, A., Elimelech, M., 2020. Towards singlespecies selectivity of membranes with subnanometre pores. Nature Nanotechnology $1-11$.

Freeman, B.D., 1999. Basis of permeability/selectivity tradeoff relations in polymeric gas separation membranes. Macromolecules 32 (2), 375-380.

Freger, V., 2003. Nanoscale heterogeneity of polyamide membranes formed by interfacial polymerization. Langmuir 19 (11), 4791-4797.

Fridman-Bishop, N., Freger, V., 2017. What makes aromatic polyamide membranes superior: New insights into ion transport and membrane structure. Journal of Membrane Science 540, 120-128.

Fujioka, T., Kodamatani, H., Nghiem, L.D., Shintani, T., 2019. Transport of NNitrosamines through a Reverse Osmosis Membrane: Role of Molecular Size and Nitrogen Atoms. Environ. Sci. Technol. Let. 6 (1), 44-48.

Fujioka, T., Oshima, N., Suzuki, R., Khan, S.J., Roux, A., Poussade, Y., Drewes, J.E., Nghiem, L.D., 2013. Rejection of small and uncharged chemicals of emerging concern by reverse osmosis membranes: The role of free volume space within the active skin layer. Separation and Purification Technology 116, 426-432.

Fujioka, T., Oshima, N., Suzuki, R., Price, W.E., Nghiem, L.D., 2015. Probing the internal structure of reverse osmosis membranes by positron annihilation spectroscopy: Gaining more insight into the transport of water and small solutes. Journal of membrane science 486, 106-118.

Geankopolis, C.J., 1993. Transport processes and unit operations. Prentice-Hall.

Geise, G.M., Lee, H.S., Miller, D.J., Freeman, B.D., McGrath, J.E., Paul, D.R., 2010. Water purification by membranes: the role of polymer science. Journal of Polymer Science Part B: Polymer Physics 48 (15), 1685-1718.

Geise, G.M., Park, H.B., Sagle, A.C., Freeman, B.D., McGrath, J.E., 2011. Water permeability and water/salt selectivity tradeoff in polymers for desalination. J. Membr. Sci. 369 (1-2), 130-138.

Geise, G.M., Paul, D.R., Freeman, B.D., 2014. Fundamental water and salt transport properties of polymeric materials. Prog. Polym. Sci. 39 (1), 1-42.

Ghosh, A.K., Jeong, B.-H., Huang, X., Hoek, E.M.V, 2008. Impacts of reaction and curing conditions on polyamide composite reverse osmosis membrane properties. J. Membr. Sci. 311 (1-2), 34-45.

Greenlee, L.F., Lawler, D.F., Freeman, B.D., Marrot, B., Moulin, P., 2009. Reverse osmosis desalination: water sources, technology, and today's challenges. Water research 43 (9), 2317-2348.

Gu, J.-E., Jun, B.-M., Kwon, Y.-N., 2012. Effect of chlorination condition and permeability of chlorine species on the chlorination of a polyamide membrane. Water Res 46 (16), 5389-5400.

Hannesschlaeger, C., Horner, A., Pohl, P., 2019. Intrinsic membrane permeability to small molecules. Chemical reviews 119 (9), 5922-5953.

Hiemenz, P.C., Lodge, T.P., 2007. Polymer chemistry. CRC press.

Jons, S.D., Stutfs, K.J. and Ferritfo, M.S. Treatment of composite polyamide membrane to improve performance.

Kargol, A., 2000. Modified Kedem-Katchalsky equations and their applications. J. Membr. Sci. 174 (1), 43-53.

Kibler, R., Mohrhardt, B., Zhang, M., Breitner, L., Howe, K.J., Minakata, D., 2020. Group Contribution Method to Predict the Mass Transfer Coefficients of Organics through Various RO Membranes. Environmental Science \& Technology 54 (8), 5167-5177.

Kim, S., Chu, K.H., Al-Hamadani, Y.A.J., Park, C.M., Jang, M., Kim, D.-H., Yu, M., Heo, J., Yoon, Y, 2018. Removal of contaminants of emerging concern by membranes in water and wastewater: a review. Chemical Engineering Journal 335, 896-914.

Kim, T.-U., Drewes, J.E., Scott Summers, R., Amy, G.L., 2007. Solute transport model for trace organic neutral and charged compounds through nanofiltration and reverse osmosis membranes. Water Res 41 (17), 3977-3988. 
Kimura, K., Amy, G., Drewes, J.E., Heberer, T., Kim, T.-U., Watanabe, Y., 2003. Rejection of organic micropollutants (disinfection by-products, endocrine disrupting compounds, and pharmaceutically active compounds) by NF/RO membranes. Journal of Membrane Science 227 (1), 113-121.

Kimura, K., Toshima, S., Amy, G., Watanabe, Y., 2004. Rejection of neutral endocrine disrupting compounds (EDCs) and pharmaceutical active compounds (PhACs) by RO membranes. Journal of Membrane Science 245 (1), 71-78.

Kong, F.-X., Yang, H.-W., Wu, Y.-q., Wang, X.-m., Xie, Y.F., 2015. Rejection of pharmaceuticals during forward osmosis and prediction by using the solution-diffusion model. Journal of Membrane Science 476, 410-420.

Koros, W.J., Zhang, C., 2017. Materials for next-generation molecularly selective synthetic membranes. Nature Materials 16 (3), 289-297.

Lee, J., Doherty, C.M., Hill, A.J., Kentish, S.E., 2013. Water vapor sorption and free volume in the aromatic polyamide layer of reverse osmosis membranes. J. Membr. Sci. 425, 217-226.

Lide, D.R., 2004. CRC handbook of chemistry and physics. CRC press.

Lin, L., Feng, C., Lopez, R., Coronell, O., 2016a. Identifying facile and accurate methods to measure the thickness of the active layers of thin-film composite membranes-A comparison of seven characterization techniques. Journal of membrane science 498, 167-179.

Lin, L., Lopez, R., Ramon, G.Z., Coronell, O., 2016b. Investigating the void structure of the polyamide active layers of thin-film composite membranes. J. Membr. Sci. 497, 365-376.

Liu, M., Wu, D., Yu, S., Gao, C., 2009. Influence of the polyacyl chloride structure on the reverse osmosis performance, surface properties and chlorine stability of the thinfilm composite polyamide membranes. J. Membr. Sci. 326 (1), 205-214.

Madaeni, S.S., 1999. The application of membrane technology for water disinfection. Water Res 33 (2), 301-308.

Marcus, Y., 2015. Ions in Solution and their Solvation. Wiley Online Library.

MarvinSketch 19.11.0, 2019. ChemAxon (http://www. chemaxon. com).

Miyashita, Y., Park, S.-H., Hyung, H., Huang, C.-H., Kim, J.-H., 2009. Removal of N -Nitrosamines and Their Precursors by Nanofiltration and Reverse Osmosis Membranes. Journal of Environmental Engineering 135 (9), 788-795.

Mulder, J., 2012. Basic principles of membrane technology. Springer Science \& Business Media.

Pacheco, F.A., Pinnau, I., Reinhard, M., Leckie, J.O., 2010. Characterization of isolated polyamide thin films of RO and NF membranes using novel TEM techniques. J. Membr. Sci. 358 (1-2), 51-59.

Park, H.B., Kamcev, J., Robeson, L.M., Elimelech, M., Freeman, B.D., 2017. Maximizing the right stuff: The trade-off between membrane permeability and selectivity. Science 356 (6343), eaab0530.

Paul, D.R., 2004. Reformulation of the solution-diffusion theory of reverse osmosis. J. Membr. Sci. 241 (2), 371-386.

Peter-Varbanets, M., Zurbrügg, C., Swartz, C., Pronk, W., 2009. Decentralized systems for potable water and the potential of membrane technology. Water Res 43 (2), 245-265.

Petersen, R.J., 1993. Composite reverse osmosis and nanofiltration membranes. Journal of membrane science 83 (1), 81-150.

Radjenović, J., Petrović, M., Ventura, F., Barceló, D., 2008. Rejection of pharmaceuticals in nanofiltration and reverse osmosis membrane drinking water treatment. Water Res 42 (14), 3601-3610.

Robeson, L.M., 2008. The upper bound revisited. J. Membr. Sci. 320 (1-2), 390-400.

Robeson, L.M., Freeman, B.D., Paul, D.R., Rowe, B.W., 2009. An empirical correlation of gas permeability and permselectivity in polymers and its theoretical basis. J. Membr. Sci. 341 (1-2), 178-185.

Robinson, R.A., Stokes, R.H., 2002. Electrolyte solutions. Courier Corporation.

Rodriguez-Narvaez, O.M., Peralta-Hernandez, J.M., Goonetilleke, A., Bandala, E.R., 2017. Treatment technologies for emerging contaminants in water: a review. Chemical Engineering Journal 323, 361-380.

Rudan-Tasic, D., Klofutar, C., 2003. Osmotic coefficients and solvation thermodynamics of aqueous solutions of some lower poly (ethylene glycol) s at different temperatures. J. Mol. Liq. 103, 187-200.

Sanders, D.F., Smith, Z.P., Guo, R., Robeson, L.M., McGrath, J.E., Paul, D.R., Freeman, B. D., 2013. Energy-efficient polymeric gas separation membranes for a sustainable future: A review. Polymer 54 (18), 4729-4761.

Sanders, E.S., 1988. Penetrant-induced plasticization and gas permeation in glassy polymers. J. Membr. Sci. 37 (1), 63-80.

Shannon, M.A., Bohn, P.W., Elimelech, M., Georgiadis, J.G., Mariñas, B.J., Mayes, A.M., 2008. Science and technology for water purification in the coming decades. Nature 452 (7185), 301-310.

Sherwood, T.K., Brian, P.L.T., Fisher, R.E, 1967. Desalination by reverse osmosis. Industrial \& Engineering Chemistry Fundamentals 6 (1), 2-12.

Shimazu, A., Ikeda, K., Miyazaki, T., Ito, Y., 2000. Application of positron annihilation technique to reverse osmosis membrane materials. Radiation Physics and Chemistry 58 (5-6), 555-561.

Sholl, D.S., Lively, R.P., 2016. Seven chemical separations: to change the world: purifying mixtures without using heat would lower global energy use, emissions and pollution-and open up new routes to resources. Nature 532 (7600), 435-438.
Song, X., Gan, B., Qi, S., Guo, H., Tang, C.Y., Zhou, Y., Gao, C., 2020. Intrinsic Nanoscale Structure of Thin Film Composite Polyamide Membranes: Connectivity, Defects, and Structure-Property Correlation. Environ. Sci. Technol. 54 (6), 3559-3569.

Song, Y., Sun, P., Henry, L.L., Sun, B., 2005. Mechanisms of structure and performance controlled thin film composite membrane formation via interfacial polymerization process. Journal of membrane science 251 (1-2), 67-79.

Soroush, A., Barzin, J., Barikani, M., Fathizadeh, M., 2012. Interfacially polymerized polyamide thin film composite membranes: Preparation, characterization and performance evaluation. Desalination 287, 310-316.

Steinle-Darling, E., Zedda, M., Plumlee, M.H., Ridgway, H.F., Reinhard, M., 2007. Evaluating the impacts of membrane type, coating, fouling, chemical properties and water chemistry on reverse osmosis rejection of seven nitrosoalklyamines, including NDMA. Water Research 41 (17), 3959-3967.

Stokes, R.H., Robinson, R.A., 1966. Interactions in aqueous nonelectrolyte solutions. I. Solute-solvent equilibria. J. Phys. Chem. 70 (7), 2126-2131.

Stolov, M., Freger, V., 2019. Degradation of polyamide membranes exposed to chlorine: an impedance spectroscopy study. Environ. Sci. Technol. 53 (5), 2618-2625.

Surawanvijit, S., Rahardianto, A., Cohen, Y., 2016. An integrated approach for characterization of polyamide reverse osmosis membrane degradation due to exposure to free chlorine. J. Membr. Sci. 510, 164-173.

Teplyakov, V., Meares, P., 1990. Correlation aspects of the selective gas permeabilities of polymeric materials and membranes. Gas Separation \& Purification 4 (2), 66-74.

Uedaira, H., Uedaira, H., 1969. Activity coefficients of aqueous xylose and maltose solutions. Bull. Chem. Soc. Jpn. 42 (8), 2137-2140.

Verbeke, R., Gomez, V., Vankelecom, I.F.J, 2017. Chlorine-resistance of reverse osmosis (RO) polyamide membranes. Prog. Polym. Sci. 72, 1-15.

Verliefde, A.R.D., Cornelissen, E.R., Heijman, S.G.J., Hoek, E.M.V., Amy, G.L., Bruggen, B.V.d., Van Dijk, J.C, 2009a. Influence of solute- membrane affinity on rejection of uncharged organic solutes by nanofiltration membranes. Environmental science \& technology 43 (7), 2400-2406.

Verliefde, A.R.D., Cornelissen, E.R., Heijman, S.G.J., Hoek, E.M.V., Amy, G.L., Bruggen, B.V.d., van Dijk, J.C, 2009b. Influence of Solute-Membrane Affinity on Rejection of Uncharged Organic Solutes by Nanofiltration Membranes. Environ. Sci. Technol. 43 (7), 2400-2406.

Wang, J., Dlamini, D.S., Mishra, A.K., Pendergast, M.T.M., Wong, M.C.Y., Mamba, B.B., Freger, V., Verliefde, A.R.D., Hoek, E.M.V, 2014a. A critical review of transport through osmotic membranes. J. Membr. Sci. 454, 516-537.

Wang, J., Mo, Y., Mahendra, S., Hoek, E.M.V, 2014b. Effects of water chemistry on structure and performance of polyamide composite membranes. Journal of membrane science 452, 415-425.

Wang, Z., Deshmukh, A., Du, Y., Elimelech, M., 2020. Minimal and zero liquid discharge with reverse osmosis using low-salt-rejection membranes. Water Research 170, 115317.

Werber, J.R., Deshmukh, A., Elimelech, M., 2016a. The Critical Need for Increased Selectivity, Not Increased Water Permeability, for Desalination Membranes. Environ. Sci. Technol. Let. 3 (4), 112-120.

Werber, J.R., Osuji, C.O., Elimelech, M., 2016b. Materials for next-generation desalination and water purification membranes. Nature Reviews Materials 1 (5), 16018.

Wijmans, J.G., Baker, R.W., 1995. The solution-diffusion model: a review. J. Membr. Sci. 107 (1-2), 1-21.

Williams, M.E., Hestekin, J.A., Smothers, C.N., Bhattacharyya, D., 1999. Separation of Organic Pollutants by Reverse Osmosis and Nanofiltration Membranes: Mathematical Models and Experimental Verification. Industrial \& Engineering Chemistry Research 38 (10), 3683-3695.

Wu, S., Xing, J., Zheng, C., Xu, G., Zheng, G., Xu, J., 1997. Plasma modification of aromatic polyamide reverse osmosis composite membrane surface. Journal of Applied Polymer Science 64 (10), 1923-1926.

Xie, M., Nghiem, L.D., Price, W.E., Elimelech, M., 2012. Comparison of the removal of hydrophobic trace organic contaminants by forward osmosis and reverse osmosis. Water Research 46 (8), 2683-2692.

Xie, M., Nghiem, L.D., Price, W.E., Elimelech, M., 2014. Relating rejection of trace organic contaminants to membrane properties in forward osmosis: Measurements, modelling and implications. Water Research 49, 265-274.

Yan, H., Miao, X., Xu, J., Pan, G., Zhang, Y., Shi, Y., Guo, M., Liu, Y., 2015. The porous structure of the fully-aromatic polyamide film in reverse osmosis membranes. J. Membr. Sci. 475, 504-510.

Yang, Z., Guo, H., Tang, C.Y., 2019. The upper bound of thin-film composite (TFC) polyamide membranes for desalination. J. Membr. Sci., 117297

Yangali-Quintanilla, V., Sadmani, A., McConville, M., Kennedy, M., Amy, G., 2010. A QSAR model for predicting rejection of emerging contaminants (pharmaceuticals, endocrine disruptors) by nanofiltration membranes. Water Research 44 (2), 373-384.

Yangali-Quintanilla, V., Verliefde, A., Kim, T.U., Sadmani, A., Kennedy, M., Amy, G., 2009. Artificial neural network models based on QSAR for predicting rejection of neutral organic compounds by polyamide nanofiltration and reverse osmosis membranes. Journal of Membrane Science 342 (1), 251-262.

Yaroshchuk, A.E., 1995. Solution-diffusion-imperfection model revised. Journal of Membrane Science 101 (1-2), 83-87. 
Yip, N.Y., Elimelech, M., 2011. Performance limiting effects in power generation from salinity gradients by pressure retarded osmosis. Environmental science \& technology 45 (23), 10273-10282.

Yip, N.Y., Tiraferri, A., Phillip, W.A., Schiffman, J.D., Elimelech, M., 2010. High performance thin-film composite forward osmosis membrane. Environ. Sci. Technol. 44 (10), 3812-3818.

Yip, N.Y., Tiraferri, A., Phillip, W.A., Schiffman, J.D., Hoover, L.A., Kim, Y.C., Elimelech, M., 2011. Thin-film composite pressure retarded osmosis membranes for sustainable power generation from salinity gradients. Environmental science \& technology 45 (10), 4360-4369.
Yoon, Y., Westerhoff, P., Snyder, S.A., Wert, E.C., Yoon, J., 2007. Removal of endocrine disrupting compounds and pharmaceuticals by nanofiltration and ultrafiltration membranes. Desalination 202 (1), 16-23.

Zhang, H., Geise, G.M., 2016. Modeling the water permeability and water/salt selectivity tradeoff in polymer membranes. J. Membr. Sci. 520, 790-800.

Zhang, M., Breitner, L., Howe, K.J., Minakata, D., 2020. The role of interaction between low molecular weight neutral organic compounds and a polyamide RO membrane in the rejection mechanism. RSC Advances 10 (26), 15642-15649.

Zhang, X., Cahill, D.G., Coronell, O., Mariñas, B.J., 2009. Absorption of water in the active layer of reverse osmosis membranes. J. Membr. Sci. 331 (1-2), 143-151. 